Pecvnia, Monográfico (2009), pp. 77-154

\title{
Las inversiones financieras
}

\author{
Alicia Rodríguez Pérez \\ alicia.rodriguez@unileon.es \\ Universidad de León \\ Fac. de Ciencias Económicas y Empresariales \\ Campus de Vegazana, $\mathrm{s} / \mathrm{n}$ \\ 24071 León (España)
}

\section{INTRODUCCIÓN}

Uno de los ámbitos en el que el nuevo PGC ha introducido novedades más significativas es en la valoración y registro contable de las inversiones financieras, y ello por varias razones.

En los últimos años, impulsado por el fenómeno de globalización económica, hemos asistido a un desarrollo de los mercados financieros sin precedentes, hasta tal punto que en la actualidad la gestión de recursos y riesgos financieros ocupa un lugar estratégico en la gestión empresarial. Así, la participación de las empresas en los mercados financieros se ha incrementado de forma importante, bien como mecanismo de financiación alternativo al crédito bancario, o bien como forma de gestionar profesionalmente excedentes de liquidez mediante la 
adquisición de instrumentos financieros emitidos por otras empresas. En consecuencia, el peso relativo de estos instrumentos en el balance de las entidades ha aumentado significativamente, lo que exige ofrecer información útil y relevante a los usuarios que facilite la adopción de sus decisiones.

Sin embargo, los sistemas contables tradicionales, con una clara orientación a la protección del patrimonio, sin olvidar la influencia fiscal a la que han estado sometidos, se muestran claramente insuficientes para ofrecer esta información. En ellos, los instrumentos financieros se han considerado utilizando criterios excesivamente rígidos que conceden un tratamiento homogéneo tanto al registro como a la valoración de las inversiones financieras, sin tener en cuenta la finalidad de la inversión o su función en la estrategia de la política de inversiones y gestión de riesgos de la empresa.

En este contexto, las normas Internacionales de Contabilidad (NIC) han tratado de mejorar de forma significativa el marco contable, marcando las pautas a seguir en la NIC "32. Instrumentos Financieros, Presentación e Información a Revelar", en la NIC "39. Instrumentos Financieros, Reconocimiento y Valoración", en la NIIF "07. Instrumentos Financieros: información a revelar", así como en las Interpretaciones emitidas por el Internacional Financial Reporting Interpretations Committee (IFRIC), fundamentalmente la IFRIC-02 e IFRIC-09. Precisamente, estas Normas Internacionales han sufrido una rápida evolución en los últimos años, y han estado sometidas a un proceso continuo de revisión y modificación, en ese afán permanente de garantizar que los usuarios de los estados financieros reciban información relevante de cómo las entidades crean o transforman valor mediante la utilización de los instrumentos financieros.

Por su parte, el nuevo PGC destaca en la parte Introductoria "su vocación de convergencia con los Reglamentos Comunitarios que contienen las NIC/NIIF adoptadas, en todos aquellos aspectos que resultan necesarios para hacer compatibles ambos cuerpos normativos contables..." de forma que, en el tema que nos ocupa, el tratamiento contable de las inversiones financieras, es donde se observa un mayor seguimiento y adaptación a la indicada normativa internacional. En consecuencia, las modificaciones que se pueden apreciar respecto del tratamiento contable recogido en el ya derogado Plan de 1990, son tan importantes que bien se pudiera decir que nada, o casi nada, de la contabilización tradicional está presente en los nuevos conceptos y soluciones que se van a exponer. 
Por ello, en los siguientes apartados, comenzamos haciendo una breve revisión conceptual de lo que hasta ahora se consideran como "inversiones financieras" y que según la terminología de las NIC forman parte de lo que denominan "Instrumentos Financieros", concepto más amplio que el tradicional de inversiones o activos financieros. Este concepto, nos permite efectuar una clasificación de las inversiones financieras atendiendo a diversos criterios que también son utilizados por el derogado PGC y que permanecen en el nuevo texto contable.

Seguidamente, abordamos uno de los mayores problemas que se deriva del tratamiento contable de estas inversiones como es el de su valoración, cuestión que supone un enfrentamiento entre los dos criterios de valoración más conocidos, precio de coste o valor de mercado, planteando, al mismo tiempo, otras alternativas que se derivan de la normativa internacional, como son el denominado valor razonable y el coste amortizado, los cuales se aplican a determinadas categorías de activos financieros.

Precisamente, y en función de estos nuevos criterios de valoración, se efectúa, a continuación, un análisis de la composición, valoración, deterioros y baja de los diferentes tipos de activos que integran las tres carteras de valores más importantes que se distinguen en la normativa contable internacional y, por ende, en el nuevo PGC, para lo cual se estudia el contenido de la norma de registro y valoración $n^{\circ} 9$ incluida en la segunda parte de dicho texto contable.

Por último, dado que en la mayor parte de las entidades las inversiones financieras se centran básicamente en títulos de renta fija o variable, nos detendremos en analizar el tratamiento y desarrollo contable de toda la operatoria que generan ambos tipos de inversiones, contemplado desde un punto de vista eminentemente práctico.

\section{CONCEPTO Y CLASIFICACIÓN DE LAS INVERSIONES} FINANCIERAS

En el Marco Conceptual del PGC se considera que los activos son recursos controlados económicamente por la empresa de los que se espera obtener beneficios económicos futuros y que surgen como consecuencia de transacciones o sucesos pasados. Puesto que la obtención de un activo implica, normalmente, la realización de un desembolso o 
inversión de fondos, suele considerarse el término "activo" en general equiparable, en muchas ocasiones, al de inversiones.

De esta forma, en el balance de las entidades, junto a inversiones de carácter real, como bienes o derechos sobre edificios, instalaciones, patentes, existencias, etc., que utilizan con carácter habitual en sus procesos productivos y comerciales, existen otros bienes, como acciones emitidas por otras compañías, préstamos y otros elementos, que se poseen como mera inversión con intenciones lucrativas (obtención de rentas o plusvalías). Es decir, estos últimos activos dan derecho en sí mismos y de forma directa a recibir otros medios líquidos, no estando encaminados hacia una actividad de explotación, sino que más bien forman parte de la gestión financiera de las empresas que, en la actualidad, puede ser tan importante como la productiva. El conjunto de estos bienes se incluye dentro de lo que se conoce como "activos financieros".

Así pues, las inversiones financieras representan activos o instrumentos financieros poseídos por las empresas que se adquieren, normalmente, a través de su contratación o negociación en el mercado de capitales. Tienen como finalidad aumentar la riqueza de la empresa, bien sea como consecuencia de los rendimientos que generan, de su revalorización $\mathrm{o}$ de otros beneficios derivados de las relaciones $u$ operaciones que se pueden realizar con ellas (cesiones temporales, transferencias, préstamos de valores, etc.).

Se representan por títulos-valores, anotaciones en cuenta u otros documentos mercantiles emitidos por otras entidades con la finalidad de captar nuevos recursos financieros, ya sean propios o ajenos, según sea la naturaleza del título emitido, de tal forma que los mismos títulos suponen para ellas un pasivo financiero o un instrumento de patrimonio. Es decir, se pueden considerar a las inversiones financieras, si se contemplan desde el punto de vista de la entidad inversora, como activos financieros, mientras que para la entidad emisora representan partes de un capital o préstamo en cualquiera de sus manifestaciones.

Esta es la concepción utilizada por el nuevo PGC el cual, en consonancia con la NIC 32 define un instrumento financiero como "un contrato que da lugar a un activo financiero en una empresa $y$, simultáneamente, a un pasivo financiero o a un instrumento de patrimonio en otra empresa" (PGC 2007, 2 ${ }^{\mathrm{a}}$ parte: Normas de registro y valoración, norma $9^{a}$ ). 
Como se puede observar, el concepto de "Instrumento Financiero" que utiliza tanto el Plan como la normativa internacional del IASB es más amplio, al referirse tanto a "activos" como a "pasivos" financieros, considerando dentro de ambos términos las siguientes partidas:

a) Activos financieros:

- Efectivo y otros activos líquidos equivalentes.

- Créditos por operaciones comerciales: clientes y deudores varios.

- Créditos a terceros, tales como los préstamos y créditos financieros concedidos, incluidos los surgidos en la venta de activos no corrientes.

- Valores representativos de deuda adquiridos: obligaciones, bonos y pagarés.

- Instrumentos de patrimonio de otras empresas adquiridos: acciones, participaciones en instituciones de inversión colectiva.

- Derivados con valoración favorable para la empresa: futuros, opciones, permutas financieras y compraventa de moneda extranjera a plazo, y

- Otros activos financieros, tales como depósitos en entidades de crédito, anticipos y créditos al personal, fianzas y depósitos constituidos, dividendos a cobrar y desembolsos exigidos sobre instrumentos de patrimonio.

b) Pasivos financieros:

- Débitos por operaciones comerciales: proveedores y acreedores varios.

- Deudas con entidades de crédito.

- Obligaciones y otros valores negociables emitidos: bonos, pagarés.

- Derivados con valoración desfavorable para la empresa: futuros, opciones, permutas financieras y compraventa de moneda extranjera a plazo.

- Deudas con características especiales, y

- Otros pasivos financieros: deudas con terceros, tales como préstamos y créditos financieros recibidos de personas o empresas que no sean entidades de crédito, incluidos los surgidos en la compra de activos no corrientes, fianzas y depósitos recibidos y desembolsos exigidos por terceros sobre participaciones. 
Asimismo, el nuevo texto contable considera también como "instrumentos financieros" los instrumentos de patrimonio propio, esto es, las acciones ordinarias emitidas por la propia sociedad que se incluyen dentro de los fondos propios.

Ahora bien, dado el objetivo del presente tema, nos centraremos exclusivamente en analizar la problemática contable que plantean ciertos activos financieros, es decir, estudiaremos las inversiones financieras desde el punto de vista del inversor; prescindiendo, por tanto, del estudio del resto de activos financieros, dado que tradicionalmente no se han incluido dentro del término genérico "inversiones financieras" al no tratarse de valores negociables.

Por otra parte, la naturaleza dinámica de los mercados financieros, que han experimentado un desarrollo sin precedentes en los últimos treinta años, ha estimulado una extraordinaria gama de inversiones financieras, desde las más tradicionales, tales como bonos, pagarés de empresas, letras bursátiles, etc., hasta las diversas formas de instrumentos derivados como opciones y permutas financieras. En consecuencia, dada la gran variedad de activos o instrumentos financieros que se pueden considerar, se hace necesario plantear una clasificación que facilite su identificación, sobre todo desde el punto de vista del diferente tratamiento contable que exigen en cada caso. En este punto, se pueden adoptar distintos criterios a la hora de clasificar las inversiones financieras, entre los que destacan:

1. El plazo de recuperación o tiempo de permanencia de la inversión, según el cual las inversiones financieras pueden ser de dos tipos: temporales o a corto plazo (forman parte del denominado activo corriente o circulante) y permanentes o a largo plazo (incluidas en el inmovilizado financiero). El PGC de 2007 utiliza como criterio delimitador entre el activo corriente y no corriente el ciclo normal de explotación, es decir, el periodo de tiempo que transcurre entre la adquisición de los activos que se incorporan al proceso productivo y la realización de los activos en forma de efectivo o equivalente (periodo medio de maduración), de tal forma que si el activo en cuestión se espera consumir, vender, o realizar en el transcurso del ciclo normal de explotación se incluirá en el activo corriente y fuera de dicho activo, en caso contrario. Ahora bien, tratándose de inversiones financieras a las que no es de aplicación el criterio anterior, se incluirán en el activo corriente si su vencimiento, enajenación o realización se espera que se produzca 
en el plazo máximo de un año, contado a partir de la fecha de cierre del ejercicio. En consecuencia, los activos financieros no corrientes se clasificarán en corrientes en la parte que corresponda.

2. La finalidad de su adquisición, que permite distinguir entre:

a. Inversiones de rentabilidad o cartera de renta: tienen como principal objetivo la percepción de los rendimientos (intereses o dividendos) que se derivan de ellas, por lo que, normalmente, son de carácter permanente.

b. Inversiones de control o cartera de control, a través de las cuales se desea ejercer un dominio o influencia notable en la entidad emisora de dichos títulos, razón por la cual estas inversiones se mantendrán de forma indefinida en el tiempo.

c. Inversiones de negociación o especulación, que pretenden conseguir plusvalías como consecuencia del mayor valor que pueden alcanzar dichas inversiones en el mercado y que motivaría la enajenación inmediata de las mismas, por ello, generalmente, tendrán carácter temporal a muy corto plazo.

3. La naturaleza de la inversión, criterio que nos permite diferenciar entre inversiones que representan aportaciones a título de capital, las que otorgan un derecho de crédito y las de rentas varias o no definidas, como las inmobiliarias o las inversiones en bienes de alto valor negociable.

4. El carácter monetario o no monetario, según el cual se pueden identificar:

a. Inversiones financieras monetarias, para las que se conoce la fecha en la que se van a convertir en liquidez, el rendimiento que generan y el importe exacto que se va a recuperar en la fecha de su amortización o reembolso.

b. Inversiones financieras no monetarias, en las que se desconocen los aspectos anteriores.

5. El tipo de renta que devengan, en función del cual existen valores de renta fija (inversiones financieras monetarias) y valores de renta variable (inversiones financieras no monetarias). La diferencia fundamental entre los valores de renta fija y las participaciones en capital o valores de renta variable está en que la posesión de los primeros no otorga derecho a ejercer influencia alguna en las entidades emisoras (públicas o privadas), de forma que la 
empresa tenedora es simplemente un acreedor con los derechos correspondientes a los mismos; por el contrario, los inversores en renta variable son socios (accionistas, en su caso) de la empresa por lo que poseen los derechos legales que se derivan de tal condición.

El PGC de 2007, al igual que su predecesor, utiliza una combinación de los criterios anteriores a efectos de su presentación y reconocimiento en el Balance, teniendo en cuenta que estos activos se reconocerán en dicho estado financiero cuando la empresa se convierta en una parte obligada del contrato o negocio jurídico conforme a las disposiciones del mismo.

Así, en el modelo de Balance que se propone en la tercera parte del nuevo texto contable, las inversiones financieras se clasifican, en primer lugar, atendiendo a su vencimiento en activos no corrientes y corrientes. Dentro de cada una de estas dos grandes masas patrimoniales, tales inversiones se distinguen según la relación e influencia que se ejerza sobre la entidad emisora de los títulos, separando las inversiones en empresas del grupo y asociadas del resto y, por último, dentro de cada una de estas submasas patrimoniales la clasificación se efectúa en función de la naturaleza de los títulos, esto es, participaciones en instrumentos de patrimonio, por un lado, y valores representativos de deuda por otro.

Sin embargo, una de las clasificaciones que más novedad supone en la nueva normativa contable española, pero ya bastante conocida en la normativa internacional, así como en las normas Statements of Financial Accounting Standards (SFAS) emitidas por el Financial Accounting Standards Board (FSAB) de Estados Unidos ${ }^{1}$, es la que se efectúa en función del criterio de valoración que se utilice para los títulos. De esta forma los activos financieros se clasificarán en alguna de las siguientes categorías:

a) Préstamos y partidas a cobrar.

b) Inversiones mantenidas hasta el vencimiento.

c) Activos financieros mantenidos para negociar.

d) Otros activos financieros a valor razonable con cambios en la cuenta de pérdidas y ganancias.

\footnotetext{
Véase, al respecto El Statements of Financial Accounting Standard (SFAS) $\mathrm{n}^{\circ}$ 107 (FASB 1991) y el Statement of Financial Accounting Standard (SFAS) $n^{\circ} 115$ (FASB 1993).
} 
e) Inversiones en el patrimonio de empresas del grupo, multigrupo y asociadas.

f) Activos financieros disponibles para la venta.

La composición de cada una de estas carteras, y el análisis de la problemática contable que plantean, sobre todo desde el punto de vista de su valoración, es objeto de estudio en los próximos apartados, a excepción de los préstamos y partidas a cobrar que, como ya indicamos, cae fuera de los objetivos de este tema.

\section{VALORACIÓN DE LAS INVERSIONES FINANCIERAS}

La medición y valoración de los distintos activos que integran la estructura económica de una empresa puede hacerse mediante la utilización de diferentes criterios como por ejemplo, coste histórico, valor de mercado, valor neto realizable, valor actual, entre otros.

Ante las alternativas anteriores, parece ser que en la práctica y con relación a las inversiones financieras, el conflicto se manifiesta, fundamentalmente, entre la utilización del coste histórico o el valor de mercado existiendo argumentos tanto a favor como en contra de ambos criterios, por lo que nos centraremos básicamente en el análisis de estos dos criterios de valoración y sus variantes, valor razonable y coste amortizado.

\section{inconvenientes}

3.1. Valoración por el "coste histórico": ventajas e

La Contabilidad tradicional ha venido utilizando como principio de valoración generalmente aceptado para las partidas del activo del balance el coste histórico, criterio que viene unido estrechamente al principio de prudencia de forma que, tratándose de inversiones financieras, se aplica el valor de mercado cuando éste es inferior al de coste. De cara a su justificación desde el punto de vista teórico, se argumenta que es un valor objetivo, relevante y fiable ya que la existencia de justificantes de pago que respaldan el importe abonado por la adquisición de un bien permite realizar su verificación, con un bajo coste de obtención de información sobre dicho valor.

Sin embargo, la relevancia del coste histórico solamente se cumple en el momento inicial de la adquisición, ya que con posterioridad 
en el balance no aparecerá reflejado el verdadero valor de los activos de la empresa. En concreto, si se produce un aumento en el valor de dichos activos, éstos se encontrarían infravalorados al no ser objeto de ajuste contable.

Por otro lado, el empleo de la regla "coste o mercado el menor" por parte del derogado Plan contable de 1990 para valorar las inversiones financieras, implicaba que en el caso de caídas en las cotizaciones de los mercados bursátiles, las entidades poseedoras de estos títulos se veían obligadas a reflejar las correspondientes minusvalías. Ahora bien, si los mencionados títulos no formaban parte de una cartera cuyo objeto fuera la venta inmediata, podía darse la situación de que se produjera la recuperación de sus cotizaciones con anterioridad a la venta de los mismos, con lo que las pérdidas de valor, previamente trasladadas a resultados, no llegaban a producirse, con su consiguiente repercusión en la Cuenta de Pérdidas y Ganancias.

Otro de los inconvenientes que se derivan de la utilización del coste histórico, es la posible manipulación de los resultados por parte de la gerencia ya que puede vender alguna de las inversiones seleccionadas y recomprarlas inmediatamente, llevando a resultados los beneficios obtenidos a pesar de que tales transacciones no hayan variado la posición económica de la empresa. Igualmente, el empleo del coste histórico podría provocar la decisión de proceder a la venta del activo con el fin de trasladar el incremento de valor a la cuenta de pérdidas y ganancias, lo que puede no ser coherente con los objetivos a largo plazo de la entidad.

En definitiva, si bien es cierto que el coste histórico proporciona información exacta, segura y verificable, parece ser que dicha información es muy poco relevante para la toma de decisiones y no inspira, ni puede hacerlo, credibilidad ni confianza, y en este sentido, también sería poco fiable si se considera que la fiabilidad es un concepto relacionado con la confianza y credibilidad que los usuarios depositan en la información que reciben. Así, el valor global de una cartera de títulos, adquirida en varias operaciones a lo largo del tiempo y valorada a precios de adquisición, tiene muy poca o ninguna relevancia para un potencial inversor.

\section{inconvenientes}

3.2. Valoración por "valores de mercado": ventajas e

Ante los inconvenientes señalados, hace ya varias décadas en las que surgen nuevos planteamientos que proponen la oportunidad de la 
"contabilidad a precios de mercado" como criterio de valoración en sentido estricto, es decir, reconociendo no sólo las minusvalías sino también las plusvalías que se generen, con la finalidad de que los estados financieros representen la "imagen fiel" como sinónimo de "imagen económica".

Así, entre las ventajas que se derivan de la utilización de valores de mercado se pueden destacar las siguientes:

- En el caso de que se produzcan cambios de valor de los activos, se reflejará en el balance el verdadero valor de los mismos, con lo que resultará más relevante que el coste histórico.

- Permite suministrar información sobre el acierto o no de la inversión realizada en el pasado, lo que dependerá de que el valor de la misma haya experimentado el aumento o disminución que se refleja en los estados contables, es decir, el valor de mercado cumple con la característica de ser un valor de confirmación.

- En el caso de que exista un mercado organizado, ágil y profundo, esto es, que la negociabilidad de los activos esté asegurada y no se vea influenciado por la actuación de agentes privados individuales, se tratará de un valor verificable cuya conocimiento no resultará excesivamente costosa ya que la empresa empleará habitualmente dicha información para realizar la gestión de los mencionados activos.

Evidentemente, no todos los activos se intercambian en las condiciones indicadas anteriormente y aunque puedan ser objeto de una tasación independiente, el valor atribuido por la misma no sería igualmente verificable. Al mismo tiempo, puede suceder que no se cumpla con el requisito de "economicidad" si el coste de la peritación correspondiente no es compensado por los beneficios de la mayor información obtenida. Asimismo, la determinación del valor de mercado de ciertos activos puede resultar excesivamente compleja (caso de activos fijos especializados), por lo que la fiabilidad y relevancia del valor de mercado no puede garantizarse para todo tipo de activos.

Por todo ello, puede concluirse que la utilización del valor de mercado estaría justificada en el caso de activos no empleados por la empresa en su actividad generadora de ingresos y cuyo destino sea la venta en un mercado organizado que cumpla los requisitos de liquidez y 
profundidad, por lo que sería de aplicación para las inversiones financieras cotizadas.

No obstante los anterior, aún tratándose de activos financieros que reúnen las características indicadas, también se suele argumentar por parte de los detractores del valor de mercado, que la aplicación de este criterio incrementa la volatilidad de los resultados y puede ocasionar un falso sentido de seguridad así como una conducta de gestión negativa para minimizar el impacto en los estados contables.

En contraposición, puede considerarse que la volatilidad de los resultados no es excesivamente preocupante de cara a ofrecer información relevante y fiable. Los distintos agentes económicos son plenamente conscientes de que los mercados financieros no son estables y el poseer información sobre ganancias o pérdidas no realizadas puede contribuir a incrementar dicha fiabilidad y relevancia. La aplicación de valores de mercado incrementa la volatilidad de los ejercicios durante los cuales se mantiene la inversión, pero reduce la misma en los ejercicios en los que ésta se vende, momento en el que bajo valoración a coste histórico puede ser mucho mayor, dado que entonces se reflejarán todas las ganancias o pérdidas acumuladas.

Un problema importante que también puede plantearse, es la posible incompatibilidad entre este criterio de valoración y el principio de prudencia ya que el reconocimiento de ganancias no realizadas puede enmascarar los resultados ordinarios y con ello permitir el reparto de beneficios que suponen auténtico excedente, originando problemas futuros de liquidez y solvencia. Sin embargo, quizá el mayor inconveniente no está en reflejar ganancias o pérdidas no realizadas, que en definitiva constituyen información relevante, sino en el mal uso que se puede hacer de esa información. A este respecto, se puede argumentar que la cantidad de efectivo disponible para distribución vía dividendos es una cuestión de gestión financiera prudente, más que de medida del beneficio. Por ello, una posible solución al problema es ofrecer información que permita separar el denominado resultado repartible del no repartible. inconvenientes

\subsection{Valoración por el "valor razonable": ventajas e}

En la década de los años 90 , y a raíz de la polémica surgida en la valoración de las inversiones financieras al no encontrar un criterio 
de valoración totalmente satisfactorio, tanto las normas FAS de Estados Unidos, como la normas internacionales de contabilidad del IASB, evolucionan hacia un nuevo criterio de valoración que se denomina "fair value", traducido por "valor razonable" o valor justo en la terminología francesa.

Con la entrada en vigor del Reglamento de la Unión Europea CE-1606/2002 relativo a aplicación de las Normas Internacionales de Contabilidad por parte de los grupos cotizados, el criterio del valor razonable se incorpora a la legislación europea. Como consecuencia, y para dar cumplimiento a dicha normativa, en nuestro país la Ley 26/2003 de medidas fiscales, administrativas y del orden social (lo que se conoce como Ley de Acompañamiento a los Presupuestos Generales del Estado) para el año 2004, incorpora también dicho criterio de valoración.

Más recientemente, el nuevo PGC incluye en la primera parte dedicada al desarrollo del Marco Conceptual de la Contabilidad, entre otros criterios de valoración (coste histórico, valor neto realizable, valor actual, coste amortizado, etc.), el valor razonable, definido en consonancia con las NIC, como:

El importe por el que puede ser intercambiado un activo o liquidado un pasivo, entre partes interesadas y debidamente informadas, que realicen una transacción en condiciones de independencia mutua. El valor razonable se determinará sin deducir los costes de transacción en los que pudiera incurrirse en su enajenación. No tendrá en ningún caso el carácter de valor razonable el que sea resultado de una transacción forzada, urgente o como consecuencia de una situación de liquidación involuntaria (PGC 2007, 1 ${ }^{\mathrm{a}}$ Parte: Marco Conceptual, Criterios de Valoración).

Para el cálculo del valor razonable se establece que, con carácter general, se efectuará por referencia a un valor de mercado fiable, considerando que el valor de cotización en un mercado activo es la mejor referencia del valor razonable. Para que un mercado pueda ser calificado como "mercado activo" tiene que cumplir las siguientes condiciones:

a) Los bienes y servicios objeto de intercambio o negociación tienen que ser homogéneos;

b) Se pueden encontrar en todo momento compradores o vendedores para un determinado bien o servicio; y

c) Los precios son conocidos y fácilmente accesibles para el público. Estos precios, además, reflejan transacciones de mercado reales, 
actuales y producidas con regularidad, es decir, no deben estar influencias por la actuación de agentes privados individuales, de forma que sean el resultado del libre juego de la oferta y la demanda.

Así pues, el valor razonable realmente viene a ser un valor de mercado cuando los activos se negocien en las condiciones anteriores, presentado las ventajas que hemos señalado anteriormente para este criterio de valoración. El problema se plantea cuando se valoren elementos para los cuales no existe un mercado activo, estableciéndose que, en este caso, el valor razonable se obtendrá mediante la aplicación de modelos y técnicas de valoración considerando como tales los siguientes:

- el empleo de referencias a transacciones recientes en condiciones de independencia mutua entre partes interesadas y debidamente informadas, si estuviesen disponibles,

- referencias al valor razonable de otros activos similares o sustancialmente iguales,

- métodos de descuento de flujos de efectivo estimados, y

- modelos generalmente utilizados para valorar opciones.

No cabe duda de que tratándose de inversiones financieras, el valor de mercado está disponible en la mayor parte de los casos, y para el resto es posible utilizar, con cierta facilidad, algunas de las técnicas indicadas, ya sea la referencia a transacciones recientes, valor de mercado de otros activos, o valor actual de los flujos esperados de efectivo. No obstante, dado que estas técnicas siempre implican un cierto nivel de subjetividad, cuando no se pueda conocer el valor razonable de forma fiable, se utilizará el precio de adquisición o el coste amortizado, minorado, en su caso, por las partidas correctoras de su valor que pudieran corresponder.

\subsection{Valoración por el coste amortizado}

Este criterio supone una variante del coste histórico que se utilizará para valorar ciertos instrumentos financieros. Así, tratándose de activos financieros, el coste amortizado se determinará a partir del importe al que inicialmente fue valorado dicho activo financiero menos los reembolsos del principal que se hubieran producido, más o menos, según proceda, la parte imputada en la cuenta de pérdidas y ganancias, 
mediante la utilización del método del tipo de interés efectivo, de la diferencia entre el importe inicial y el valor de reembolso en el vencimiento y menos cualquier reducción de valor por deterioro que hubiera sido reconocida, ya sea directamente como una disminución del importe del activo o mediante una cuenta correctora de su valor.

El tipo de interés efectivo es el tipo de actualización que iguala exactamente el valor en libros de un instrumento financiero con los flujos de efectivo estimados a lo largo de la vida del instrumento, a partir de las condiciones contractuales y sin considerar las pérdidas por riesgo de crédito futuras.

Se entiende por valor en libros o valor contable el importe neto por el que un activo o un pasivo se encuentra registrado en balance una vez deducida, en el caso de los activos, su amortización acumulada y cualquier corrección valorativa por deterioro acumulada que se haya registrado.

\section{CLASIFICACIÓN DE LAS INVERSIONES FINANCIERAS EN FUNCIÓN DE SU VALORACIÓN}

Como se ha indicado, los activos financieros, a efectos de su valoración, se pueden clasificar en alguna de las 6 categorías anteriormente indicadas; ahora bien, tratándose de inversiones financieras propiamente dichas, que a efectos de nuestro estudio están formadas básicamente por títulos representativos tanto de patrimonio como de deuda, vamos a analizar la composición y valoración de las tres carteras siguientes, sin perjuicio de que en los próximos apartados se analice la problemática que plantea su registro contable atendiendo a la tradicional separación entre valores de renta fija y renta variable.

\subsection{Cartera de Inversiones mantenidas hasta el vencimiento}

\subsubsection{Concepto}

Se pueden incluir en esta categoría los valores representativos de deuda que no sean derivados, con una fecha de vencimiento fijada, cobros de cuantía determinada o determinable y que la empresa tenga la intención efectiva y la capacidad de conservarlos hasta su vencimiento. 
Es decir, tratándose de inversiones financieras, esta cartera estará formada solamente por títulos de renta fija (los de renta variable no tienen fecha predeterminada de vencimiento) que van a permanecer en la empresa hasta que llegue el momento de su reembolso, siempre que se cuente con capacidad financiera para ello, lo que implicará que en el diseño de la política de gestión de activos y pasivos se explicite que no va a ser necesario realizar la venta anticipada de los mencionados títulos para atender a otras necesidades financieras.

El problema se plantea a la hora de demostrar que la empresa tiene tanto la intención como capacidad financiera suficiente para poder conservar los activos hasta su vencimiento. Así, en relación con la intención, el nuevo PGC establece que no se podrá clasificar ni tener clasificado ningún activo financiero como inversión a vencimiento si durante el ejercicio actual o los dos precedentes se han vendido o reclasificado activos incluidos en esta cartera por importe significante en comparación con el importe total de las inversiones mantenidas hasta vencimiento, salvo que se trate de:

a) Ventas muy próximas al vencimiento final,

b) Ventas posteriores al cobro de la práctica totalidad del principal del activo, o

c) Ventas ocasionadas por un suceso aislado y no recurrente que no podría haber sido anticipado por la entidad, como por ejemplo un deterioro importante de la capacidad de pago del deudor, cambios impositivos o de regulación o una combinación de negocios que requiera vender estos activos financieros.

Por otro lado, tal y como se establece en la NIC 39 del ISAB, la intención de las entidades de conservar los activos financieros hasta su vencimiento, no debe ser cuestionada por la existencia en el contrato de cláusulas de reembolso anticipado u opciones de compra a favor del emisor del activo, siempre y cuando el precio de recompra, o de ejercicio de la opción, no sea sustancialmente inferior al coste amortizado del instrumento para la entidad, puesto que el único efecto que tendría el ejercicio de la opción sería la anticipación del vencimiento del instrumento, no debiéndose producir un resultado significativo derivado de la cancelación anticipada.

Al igual que la intención de mantener los activos financieros hasta su vencimiento, la capacidad financiera para hacerlo debe ser 
valorada por las entidades no sólo en su reconocimiento inicial, sino también en cualquier fecha posterior. Sin embargo, el texto del nuevo PGC no especifica nada al respecto, a diferencia de la citada Norma Internacional de Contabilidad NIC 39, en la que se indica que se presume que las entidades tienen capacidad financiera para mantener las inversiones hasta su vencimiento si se dan las siguientes condiciones:

a) Tienen recursos financieros disponibles para financiar los activos hasta su vencimiento.

b) No están sujetas a limitaciones legales, o restricciones de otro tipo, que imposibiliten su intención de mantenerlos hasta la fecha de su amortización.

\subsubsection{Valoración}

Inicialmente la valoración de estos activos se efectuará por su valor razonable que, salvo evidencia en contra, será el precio de la transacción, que equivaldrá al valor razonable de la contraprestación entregada más lo gastos de transacción que les sean directamente atribuibles.

Es decir, dado que en la mayor parte de los casos, la contraprestación que se entrega para adquirir estos activos es dinero en efectivo, la valoración se efectuará por el importe total desembolsado, incluidos todos los gastos necesarios para su adquisición (corretajes, tasas, impuestos, comisiones de asesores e intermediarios, etc.) teniendo en cuenta que, tal como se indica en el apartado 2.8 de la norma de registro y valoración $n^{\circ} 9$, se deberá deducir el importe de los intereses explícitos devengados y no vencidos en el momento de la transacción (cupón corrido), el cual se registrará de forma independiente atendiendo a su vencimiento. Se entenderá por intereses "explícitos" aquellos que se obtienen de aplicar el tipo de interés contractual del instrumento financiero.

Con posterioridad a su adquisición, las inversiones mantenidas hasta vencimiento se valorarán por su coste amortizado, calculado como se explica en el apartado 3.4, debiendo contabilizar en la cuenta de pérdidas y ganancias, mediante el tipo de interés efectivo, los intereses devengados hasta la fecha. Cabe recordar que estos activos no se pretenden enajenar en el corto plazo, sino que la inversión realizada en los mismos se quiere recuperar mediante los flujos de efectivo fijados en 
el contrato, y por ello, su coste amortizado refleja mejor que su valor razonable el valor de los flujos a recibir por estos activos.

En definitiva, cuando se trata de activos financieros que se proyectan más allá del corto plazo, lo habitual es que el valor de lo entregado (en efectivo o en especie) y el valor de lo que se debe recibir a su vencimiento (valor de reembolso) no coincidan porque la transacción origina un coste financiero acumulado igual a la diferencia, cuyo efecto debe ser calculado al iniciar la inversión y repartido entre los períodos que constituyan su duración. El cálculo de este coste financiero servirá para determinar el tipo de interés efectivo de la inversión (tasa interna de rentabilidad) que permitirá distribuir la diferencia anterior entre los periodos de vida de la inversión, de forma que en cada uno de ellos se obtenga un porcentaje de interés igual sobre el importe inicial de la inversión, lo que significa aplicar el principio de devengo a los ingresos que generan estas inversiones.

En consecuencia, la aplicación del método de interés efectivo implica los siguientes pasos:

a) Contabilizar inicialmente el activo financiero por su valor razonable más los costes de transacción.

b) Calcular el tipo de interés efectivo como se indica en el apartado 3.4 .

c) Aplicar el tipo de interés efectivo al valor contable del instrumento al principio de cada período, para calcular el ingreso financiero procedente del mismo.

d) Cada cobro debe ser comparado con el ingreso financiero devengado, de forma que la diferencia entre ambos importes será la amortización del principal o saldo de la inversión al comienzo del período, para calcular el saldo final.

\section{Ejemplo n ${ }^{0}$ 1.-}

Una empresa adquiere el 31 de diciembre del año X, 10 bonos de $1.000 €$ de valor nominal cada uno, emitidos por la empresa "XYZ" que se negocian en un mercado activo, siendo su valor de cotización en dicha fecha de 9.000€. Los costes de transacción liquidados por la empresa ascienden a $100 €$ y decide clasificar dichos títulos como "Inversión mantenida hasta el vencimiento" ya que tiene la intención y capacidad financiera para mantener los bonos en esta categoría. Esta inversión ofrece una rentabilidad del 5\% de interés anual liquidable cada 31 de diciembre y su amortización tendrá lugar en el plazo de 4 años por su valor nominal. 
Solución.-

Al clasificarse los bonos en la cartera de "inversiones mantenidas hasta vencimiento" deben valorarse inicialmente por su valor razonable (9.000) más los costes de transacción (100). El tipo de interés efectivo (TIE) se obtiene de la siguiente expresión:

$$
9.100=\frac{500}{(1+i)}+\frac{500}{(1+i)^{2}}+\frac{500}{(1+i)^{3}}+\frac{10.500}{(1+i)^{4}} \quad i(\mathrm{TIE}) \cong 7,699111 \%
$$

El cuadro de amortización de los bonos conforme al tipo de interés efectivo anterior es el siguiente:

\begin{tabular}{|c|c|c|c|c|}
\hline $\begin{array}{c}(\mathbf{1}) \\
\text { Fecha }\end{array}$ & $\begin{array}{c}\mathbf{( 2 )}=\mathbf{( 5 )} \times \boldsymbol{i} \\
\text { Ingresos }\end{array}$ & $\begin{array}{c}(\mathbf{3}) \\
\text { Cobros }\end{array}$ & $\begin{array}{c}\mathbf{( 4 )}=\mathbf{( 2 )}-\mathbf{( 3 )} \\
\text { Amortización }\end{array}$ & $\begin{array}{c}\mathbf{( 5 )}=\mathbf{( 5 )}+(\mathbf{4}) \\
\text { Inversión (Coste amortizado) }\end{array}$ \\
\hline $31-12-\mathrm{X}$ & & & & 9.100 \\
\hline $31-12-\mathrm{X} 1$ & 700,62 & 500 & 200,62 & $9.300,62$ \\
\hline $31-12-\mathrm{X} 2$ & 716,06 & 500 & 216,06 & $9.516,68$ \\
\hline $31-12-\mathrm{X} 3$ & 732,70 & 500 & 232,70 & $9.749,38$ \\
\hline $31-12-\mathrm{X} 4$ & 750,62 & 10.500 & $(9.749,38)$ & 0 \\
\hline
\end{tabular}

\subsubsection{Deterioro de valor}

El concepto de deterioro de valor de un instrumento financiero está relacionado con la posibilidad de recuperar o no la inversión efectuada en los diferentes activos financieros. Sin embargo, para comprender el deterioro que pueden sufrir los activos mantenidos hasta vencimiento, se debe considerar la falta de riesgo de precio en los mismos para los propósitos de la entidad, puesto que no se han adquirido con la intención de venderlos, sino de conservarlos, y a ello se ha comprometido, de ahí que estos títulos no se ven afectados por las variaciones de sus precios en el mercado. No obstante, esto no quiere decir que no estén sometidos a otros tipos de riesgos, por ejemplo los de crédito, en prácticamente todos los casos, o los riesgos de cambio, si algunos o todos los flujos derivados de los mismos están pactados en moneda diferente del euro.

Por ello, el nuevo PGC establece que, al menos al cierre del ejercicio, deberán efectuarse las correcciones valorativas necesarias siempre que exista evidencia objetiva de que el valor de un activo financiero se ha deteriorado como resultado de uno o más eventos que hayan ocurrido después de su reconocimiento inicial, y que ocasionen una reducción o retraso en los flujos de efectivo estimados futuros, como puede ser la insolvencia del deudor. 
Los eventos o sucesos que pueden causar las pérdidas por deterioro son muy variados y se derivan tanto de las dificultades financieras por las que atraviesa el emisor o deudor, como del empeoramiento de la situación económica general, o incluso de la desaparición del mercado activo para un instrumento financiero. Con frecuencia, para poder evaluar una pérdida por deterioro se necesita la elaboración de informes especiales sobre la situación económica de una determinada inversión.

Lo que no cabe duda es que el deterioro se produce bien porque disminuye el importe de los flujos de efectivo esperados (por ejemplo, a causa del impago de intereses o del principal de la deuda) o porque estos flujos se retrasen en el tiempo como consecuencia del aplazamiento en los pagos no compensado con intereses de demora. De esta forma, la pérdida por deterioro se determinará por diferencia entre el valor en libros del instrumento financiero y el valor actual de los flujos de efectivo futuros que se estima van a generar, descontados al tipo de interés efectivo calculado en el momento de su reconocimiento inicial. Para los activos financieros a tipo de interés variable, se empleará el tipo de interés efectivo que corresponda a la fecha de cierre de las cuentas anuales de acuerdo con las condiciones contractuales.

No obstante, la normativa del nuevo Plan contable establece que en el cálculo de la pérdida por deterioro de estos activos financieros se puede utilizar, como sustituto del valor actual de los flujos de efectivo futuros, su valor de mercado, siempre que éste sea suficientemente fiable como para considerarlo representativo del valor que pudiera recuperar la empresa, cuestión que se puede cumplir cuando se trate de títulos cotizados. Sin embargo, en este caso, puede darse la circunstancia de que ese valor de mercado refleje, además del riesgo de crédito por insolvencia del deudor, el riesgo de precio debido, por ejemplo, a cambios en los tipos de interés de mercado. En esta situación, puede ser muy difícil distinguir y separar, porque el mercado no lo detecta, la parte de la disminución en el valor de mercado que han experimentado los títulos que se deriva del riesgo de crédito (deterioro) de la disminución o pérdida que se debe al riesgo de precio; riesgo, que como ya se ha indicado, no afecta a estos títulos si se mantienen hasta vencimiento y que, sin embargo, se reflejaría en el cálculo del deterioro.

Las correcciones valorativas por deterioro, así como su reversión cuando el importe de dicha pérdida disminuya por causas relacionadas con un evento posterior, se reconocerán como un gasto o un ingreso, respectivamente, en la cuenta de pérdidas y ganancias. En todo 
caso, la reversión del deterioro tendrá como límite el valor en libros del activo que tendría en la fecha de reversión si no se hubiese registrado el deterioro de valor; es decir, la reversión está condicionada a que el activo no alcance un importe mayor que el correspondiente a su coste amortizado en caso de que no se hubiera producido el deterioro.

\section{Ejemplo n ${ }^{0}$ 2.-}

Con los mismos datos de ejercicio anterior, supóngase que al cierre del ejercicio X2 determinadas informaciones ponen de manifiesto que la empresa "XYZ" que atraviesa por serias dificultades financieras, ha venido retrasando los pagos a otras entidades, por lo que del análisis individualizado realizado por la empresa, se estima que los flujos de efectivo esperados son: el 60\% para el año X3 y el 20\% para el año X4.

Solución.-

La pérdida por deterioro se calculará por diferencia entre el valor en libros de los bonos a 31-12-X2 y el valor actual de los flujos de efectivo esperados, calculados al TIE; es decir:

- Valor en libros de la inversión: (coste amortizado) $=9.516,18$

- Valor actual de los flujos de efectivo esperados Vaf

$$
\text { Vaf }=\frac{500 \times 60 \%}{1+0,0769911}+\frac{10.500 \times 20 \%}{(1+0,0769911)^{2}}=2.089,04
$$

Pérdida por deterioro $=9.516,18-2.089,04=7.427,14$

\subsection{Cartera de activos financieros mantenidos para negociar}

\subsubsection{Concepto}

Las entidades adquieren cierto tipo de activos financieros con el propósito de obtener plusvalías a corto plazo derivadas de las fluctuaciones de sus precios en el mercado que motivarían su venta inmediata. Pues bien, esta cartera estará formada por valores tanto de renta fija como variable que se adquieren con la intención de beneficiarse a corto plazo de las variaciones de sus precios. En principio sólo deberán tener esta condición los valores que sean objeto de contratación en un mercado oficial que cumpla, además, las condiciones recogidas en el apartado 3.3 para la consideración de "mercado activo".

En este sentido, el PGC de 2007 establece que "se considera que un activo se posee para negociar cuando: 
a) Se origine o adquiera con el propósito de venderlo en el corto plazo,

b) Forme parte de una cartera de instrumentos financieros identificados y gestionados conjuntamente de la que existen evidencias de actuaciones recientes para obtener ganancias en el corto plazo, o

c) Sea un instrumento financiero derivado, siempre que no sea un contrato de garantía financiera ni haya sido designado como instrumento de cobertura.

Las dos primeras condiciones responden a activos que se adquieren con el propósito de obtener ganancias como consecuencia del incremento de sus precios en el mercado; es decir, la inversión realizada en estos activos se espera recuperar mediante su venta. Sin embargo, de acuerdo con la tercera condición se puede incluir en esta cartera aquellos derivados que no sean instrumentos de cobertura contable eficaz, independientemente de si se adquieren u originan con el objetivo de obtener ganancias a corto plazo; parece ser entonces, que todos los derivados que no formen parte de una cobertura contable se supone que se adquieren con el propósito de obtener resultados a corto plazo.

Una de las cuestiones que se plantea a la hora de clasificar las inversiones en esta cartera es la consideración de la amplitud o duración de lo que se entiende por "corto plazo". Tradicionalmente, en el PGC de 1990 el límite de separación entre el corto y el largo plazo estaba en el año, de tal forma que las inversiones que permanecían en poder de la empresa durante un período superior al año, se consideraban como inversiones a largo plazo.

Sin embargo, de las condiciones establecidas anteriormente para clasificar una inversión en la cartera de activos para negociar se puede deducir que la amplitud del "corto plazo" es muy inferior al período anual y la práctica así lo contempla. De hecho, en la contabilidad bancaria, en la que ya desde la Circular 4/1994 emitida por el Banco de España $^{2}$ se contempla esta cartera, se viene admitiendo de forma implícita

2 Dicha Circular ha sido derogada y sustituida por la nueva Circular 4/2004, de 22 de diciembre sobre Normas de Información Financiera Pública y reservada y Modelos de estados Financieros para Entidades de Crédito. 
(no hay una indicación específica al respecto) que la permanencia de los títulos en esta cartera no debería superar el plazo de tres meses. No obstante, excepcionalmente puede darse la circunstancia de que algunos títulos que se adquieren inicialmente para negociar, permanezcan en la entidad por un plazo incluso superior al año, si como consecuencia de un descenso brusco en sus precios se retrase la enajenación de los mismos con el fin de no obtener pérdidas.

\subsubsection{Valoración}

Como todos los activos financieros, los que se adquieren y se mantienen para negociar también se valorarán inicialmente por el valor razonable de la contraprestación entregada, es decir el precio de la transacción. Sin embargo, hay una diferencia importante con relación a la cartera anterior y es que, en este caso, los costes de transacción que sean directamente atribuibles a la adquisición de estos activos se reconocerán directamente en la cuenta de pérdidas y ganancias, es decir, se considerarán como gastos del ejercicio correspondiente.

Tratándose de instrumentos de patrimonio, formará parte de la valoración inicial el importe de los derechos preferentes de suscripción y similares que se hubiesen adquirido. Por el contrario, el importe de los dividendos acordados por el órgano competente en el momento de la adquisición, no se incluirá en la valoración inicial, dichos dividendos se registrarán de forma independiente atendiendo a su vencimiento.

Idéntico tratamiento se seguirá con relación a los intereses explícitos devengados y no vencidos en el momento de la adquisición de los títulos representativos de deudas, los cuales, como ya se indicó en la anterior cartera, se registrarán también de forma independiente atendiendo a su vencimiento.

Con posterioridad, los activos financieros mantenidos para negociar se valorarán por su valor razonable, sin deducir los gastos de transacción en que se pudiera incurrir en su enajenación. Los cambios que se produzcan en el valor razonable de un periodo a otro se imputarán en la cuenta de pérdidas y ganancias del ejercicio. Se comprende entonces, que los gastos iniciales de transacción se excluyan de la valoración inicial con el fin de que las diferencias que se presenten al comparar dos valores razonables consecutivos se deban, exclusivamente, a variaciones en el valor de mercado y no a gastos de transacción. 
Por otro lado, la contabilización de los cambios del valor razonable como gastos o ingresos del ejercicio tiene su justificación en que los activos que componen esta cartera son fácilmente realizables en el mercado y la empresa está negociando continuamente con ellos. Los mercados donde se negocian son ágiles, líquidos y profundos; es decir, son muchas las operaciones que se realizan continuamente, hay un gran volumen de contratación y siempre hay contrapartida para la operación que se quiere realizar. Las transacciones se realizan, por medio de intermediarios, a los precios de mercado que determinan el flujo de efectivo que se puede conseguir por la venta, por lo que no hay dificultades para vender, ni problemas para saber si el precio de mercado se realizará, en consecuencia, la ganancia o pérdida por diferencia entre el valor contable y el precio de mercado se considera permanentemente realizada. La utilización del coste histórico como criterio de valoración se considera irrelevante para la toma de decisiones en un entorno económico en el que la decisión de invertir en estos activos financieros se basa sólo en las expectativas de variaciones en los precios.

\subsubsection{Deterioro de valor}

Los activos financieros que se incluyen en la categoría de mantenidos para negociar quedan excluidos del cálculo del deterioro de valor porque, como ya se ha explicado, en todo momento se tiene la posibilidad de conocer su valor razonable que, para estos activos, se determinará a partir de su valor de mercado, el cual recogerá siempre cualquier deterioro de valor. De esta forma, el propio mecanismo contable de revisión periódica incorpora ya el registro del eventual deterioro y su imputación como pérdida al resultado del ejercicio. Si posteriormente, sube el valor razonable, se recuperará el deterioro y se contabilizará de forma automática como ganancia al revisar el importe de la partida de activo correspondiente.

\subsection{Cartera de activos financieros disponibles para la venta}

\subsubsection{Concepto}

Esta cartera se define por exclusión en relación con las carteras anteriores, ya que recogerá los activos financieros que no se hayan clasificado en ninguna de las dos categorías indicadas; es decir, títulos tanto de renta fija como variable que, en principio, se adquieren para obtener una rentabilidad y no con la intención de especular o 
negociar con las variaciones de sus precios. No obstante, como no están sometidos a ninguna limitación en cuanto a su venta, estos títulos pueden dar lugar también a beneficios o pérdidas derivados de su enajenación.

\subsubsection{Valoración}

La valoración inicial de los activos incluidos en esta categoría se efectuará por el valor razonable de la contraprestación entregada más los gastos de transacción que les sean directamente imputables. Para la determinación de este valor inicial debe tenerse en cuenta las indicaciones realizadas anteriormente con relación a los derechos de suscripción (mayor importe inicial), y a los dividendos anunciados pendientes de cobro e intereses explícitos devengados no vencidos (se registrarán de forma independiente).

La valoración posterior de los activos financieros disponibles para la venta se efectuará también por su valor razonable, sin deducir ningún gasto de transacción, registrando los cambios que se produzcan en el valor razonable directamente en el patrimonio neto, hasta que el activo financiero cause baja del balance o se deteriore, momento en que el importe así reconocido, se imputará a la cuenta de pérdidas y ganancias.

No cabe duda de que la mayor parte de los activos financieros de las empresas se clasificarán en esta categoría, ya que por un lado, se pueden mantener de forma indefinida, enajenándose cuando se desee, puesto que no existe limitación al respecto, y por otro, el criterio de valoración establecido hace que la incidencia de los cambios de valor en el resultado sea nula hasta el momento en el que se vendan.

No obstante, los activos financieros disponibles para la venta pueden tener otras variaciones de valor, por deterioro y por diferencias de cambio en activos financieros monetarios en moneda extranjera, que deben llevarse a resultados cuando se identifiquen y calculen.

Asimismo, se registrarán en la cuenta de pérdidas y ganancias el importe de los intereses calculados según el método del tipo de interés efectivo, y de los dividendos devengados.

Como puede observarse, en la valoración de estos activos financieros no se pierde la noción del "coste histórico" de la partida en cuestión ya que casi siempre se puede conocer a partir de la suma algebraica del valor contable de la misma y de los ajustes producidos desde el momento de la adquisición. 
Un caso particular se puede plantear cuando se trate de acciones no cotizadas, ya que lo habitual será carecer de un valor razonable para atribuir a las mismas, bien porque no tengan cotización oficial, o porque no se puede obtener un valor fiable, de forma que no se podrá practicar la revisión periódica de su valor. En tal situación, las acciones se tendrán que reconocer y mantener al coste histórico, practicando, sin embargo, las correcciones de valor que correspondan, ya que se habrán de realizar pruebas de deterioro cuando haya indicios de que el valor contable pueda haber disminuido y no se pueda recuperar.

\section{Ejemplo $n^{0}$ 3.-}

Una empresa adquiere en el ejercicio X, 4.000 obligaciones emitidas por un gobierno extranjero y suscritas por un valor unitario de $90 \$$ (cambio $1 \$=0,75 \epsilon$ ). Al cierre del ejercicio la cotización de estos títulos es de 100\$, y el tipo de cambio del dólar con respecto al euro es de $1 \$=0,70 €$.

\section{Solución.-}

- Valoración inicial: $\quad 4.000 \times 90 \times 0,75=270.000 €$

- Valor razonable (31-12-X): $4.000 \times 100 \times 0,70=280.000 €$

Es necesario distinguir, en el cambio de valor experimentado por lo títulos de 270.000 a 280.000 (diferencia positiva de $10.000 €$ ), la parte que corresponde al aumento en el valor de las cotizaciones (de 90 a 100\$), de la parte que se deriva de la devaluación experimentada por el dólar, es decir:

a) $(4.000 \times 100 \times 0,70)-(4.000 \times 90 \times 0,70)=+28.000$ diferencia que va a patrimonio neto.

b) $(4.000 \times 90 \times 0,70)-(4.000 \times 90 \times 0,75)=-18.000$ diferencia que va directamente a resultados.

\subsubsection{Deterioro de valor}

Los activos financieros disponibles para la venta también presentan la posibilidad de deterioro, aparte de la variación del valor razonable, de forma que será necesario distinguir, ante una disminución del valor razonable (por ejemplo por un descenso en la cotización) si se trata de una mera variación de precios o encubre, además, un deterioro de valor causado por un cambio significativo en las condiciones del emisor de los títulos o del prestatario correspondiente. 
Una posible forma de detectar deterioros de valor en acciones cotizadas, es observar si se produce un descenso significativo y prolongado en su valor razonable que coloque el precio por debajo del coste.

En este sentido, el nuevo PGC establece que, al menos al cierre del ejercicio, deberán efectuarse las correcciones valorativas necesarias siempre que exista evidencia objetiva de que el valor de un activo financiero disponible para la venta se ha deteriorado como resultado de uno o más eventos que hayan ocurrido desde su reconocimiento inicial y que ocasionen:

a) Un reducción o retraso en los flujos de efectivo estimados futuros, que pueden venir motivados por la insolvencia del deudor, en el caso de los instrumentos de deuda; o

b) La falta de recuperabilidad del valor en libros del activo, evidenciada, por ejemplo, por un descenso prolongado o significativo en su valor razonable, cuando se trate de instrumentos de patrimonio. En todo caso, se presumirá que el instrumento se ha deteriorado ante una caída de un año y medio y de un $40 \%$ en su cotización, sin que se haya producido la recuperación de su valor, sin perjuicio de que pudiera ser necesario reconocer una pérdida por deterioro antes de que haya transcurrido dicho plazo o descendido la cotización en el mencionado porcentaje.

La corrección valorativa por deterioro del valor de estos activos financieros será la diferencia entre su coste o coste amortizado y el valor razonable en el momento en que se efectúe la valoración, menos, en su caso, cualquier corrección valorativa por deterioro previamente reconocida en la cuenta de pérdidas y ganancias.

Las pérdidas acumuladas reconocidas en el patrimonio neto por disminución del valor razonable, siempre que exista una evidencia objetiva de deterioro en el valor del activo, se reconocerán en la cuenta de pérdidas y ganancias. Es decir, el deterioro se llevará, en primer lugar contra las revaluaciones de las cuentas de patrimonio neto, si existieran, y de no ser suficientes los saldos de estas cuentas, se cargará la diferencia a resultados del ejercicio; por el contrario, si el saldo de la cuenta de patrimonio neto fuese deudor, deberá llevarse también al resultado del ejercicio.

$\mathrm{Si}$ en ejercicios posteriores se incrementase el valor razonable, los deterioros de valor reconocidos con anterioridad pueden 
revertir, pero en este caso, tanto las NIIF, como el PGC de 2007 establecen un mecanismo cautelar con el fin de evitar la posible manipulación de resultados a través del reconocimiento y reversión de los deterioros de valor, distinguiendo tres casos:

a) Instrumentos de deuda: la corrección valorativa reconocida en ejercicios anteriores revertirá con abono a la cuenta de pérdidas y ganancias, es decir, se llevará a resultados del ejercicio al que corresponda la revalorización.

b) Instrumentos de patrimonio: dicha reversión no se llevará con abono a la cuenta de pérdidas y ganancias, sino que se registrará el incremento del valor razonable directamente contra el patrimonio neto.

c) Instrumentos de patrimonio no cotizados: para estos activos no será posible la reversión de la corrección valorativa reconocida en ejercicios anteriores.

\section{Ejemplo n ${ }^{0}$ 4.-}

Una empresa posee 10.000 acciones cotizadas de la sociedad anónima "XYZ" adquiridas el día 3 de noviembre del año $X$ a $6 € /$ acción y fueron clasificadas dentro de la categoría de "disponibles para la venta", con la intención de venderlas a medio plazo. Al cierre de dicho ejercicio el valor de mercado de estos títulos era de 8€/acción.

En el ejercicio X1, la auditoría realizada a la sociedad "XYZ" pone de manifiesto importantes irregularidades en sus cuentas anuales, de forma que el resultado calculado por la auditora es de $-4.568 .670 €$, frente al 1.350.567€ de beneficio que presentaba la empresa. En consecuencia, sus títulos han experimentado una fuerte caída en bolsa, situándose al cierre de dicho ejercicio a $3 €$ acción.

Solución.-

Las anotaciones contables que debe realizar la empresa durante los dos ejercicios afectados, $\mathrm{X}$ y X1 son las siguientes:

\begin{tabular}{|c|c|}
\hline Valor inicial $(10.000 \times 6)$ & $60.000,00$ \\
\hline Valor razonable a $31-12-\mathrm{X}(10.000 \times 8)$ & $80.000,00$ \\
\hline Diferencia positiva & $20.000,00$ \\
\hline
\end{tabular}

Anotaciones contables en el ejercicio X

3-11-X: Adquisición de los valores:

\begin{tabular}{cccc}
$60.000,00$ & $\begin{array}{l}\text { 250 IF a 1. p. en instrumentos de } \\
\text { patrimonio }\end{array}$ & $60.000,00$ \\
\hline
\end{tabular}


31-12-X: Ajustes por aplicación del nuevo valor razonable:

\begin{tabular}{cc}
$20.000,00$ & $\begin{array}{c}250 \text { IF a l. p. en instrumentos de } \\
\text { patrimonio }\end{array}$ \\
\cline { 2 - 3 } $20.000,00$ & $\begin{array}{l}\text { 900 Beneficios en activos financieros } \\
\text { disponibles para la venta }\end{array}$ \\
\hline
\end{tabular}

900 Beneficios en activos financieros disponibles para la venta

a 133 Ajustes por valoración en activos financieros disponibles para la venta

Ejercicio X1:

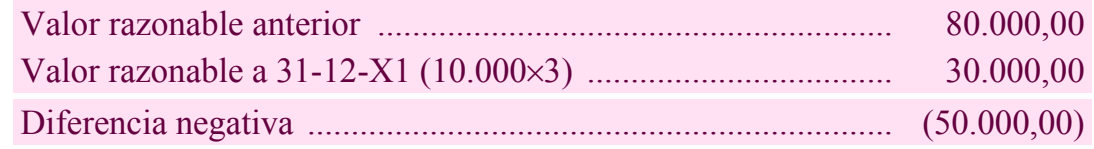

Como todavía no ha pasado año y medio, aunque los títulos han experimentado una disminución de valor superior al $40 \%$, es posible que esta diferencia negativa no se considere como deterioro y se refleje dicha variación como ajuste al nuevo valor razonable, o bien puede que se considere necesario reflejar ya la disminución en el valor de los títulos como deterioro. Se pueden dar por tanto, las dos posibilidades siguientes:

a) No considerar la diferencia negativa como deterioro y registrarla como ajuste al nuevo valor razonable a 31-12-X1:

\begin{tabular}{|c|c|c|c|c|}
\hline $50.000,00$ & $\begin{array}{l}800 \text { Pérdidas en activos financieros } \\
\text { disponibles para la venta }\end{array}$ & $\mathrm{a}$ & $\begin{array}{l}250 \mathrm{IF} \text { a } 1 . \mathrm{p} \text {. en instrumentos de } \\
\text { patrimonio }\end{array}$ & $50.000,00$ \\
\hline $50.000,00$ & $\begin{array}{l}133 \text { Ajustes por valoración en } \\
\text { activos financieros disponibles } \\
\text { para la venta }\end{array}$ & $\mathrm{a}$ & $\begin{array}{l}800 \text { Pérdidas en activos financieros } \\
\text { disponibles para la venta }\end{array}$ & $50.000,00$ \\
\hline
\end{tabular}

En balance figurarán las siguientes cuentas:

\section{ACTIVO}

IF a l.p. en instrumentos de patrim.

30.000

\section{PATRIMONIO NETO}

Ajustes por cambios de valor $(30.000)$

\section{Ejercicio X2:}

Si no se hubiese recuperado el valor de los títulos, como ha pasado más de año y medio, se debe reflejar el deterioro de valor. Las pérdidas acumuladas en el patrimonio neto se llevarán a pérdidas y ganancias:

\begin{tabular}{cc}
$30.000,00$ & $\begin{array}{l}\text { 6632 Pérdidas por valoración de } \\
\text { instrumentos financieros por su } \\
\text { valor razonable. Pérdidas de } \\
\text { disponibles para la venta }\end{array}$ \\
\cline { 2 - 2 } $30.000,00 \begin{array}{l}902 \text { Transferencias de pérdidas de } \\
\text { activos financieros disponibles } \\
\text { para la venta }\end{array}$ \\
\hline
\end{tabular}

902 Transferencias de pérdidas de activos financieros disponibles para la venta

a $\overline{133 \text { Ajustes por valoración en activos }}$ financieros disponibles para la venta $30.000,00$

Si en este ejercicio la cotización de los títulos hubiera continuado descendiendo, por ejemplo a $2 € /$ acción, además de los asientos anteriores se debe contabilizar la nueva pérdida como deterioro: 


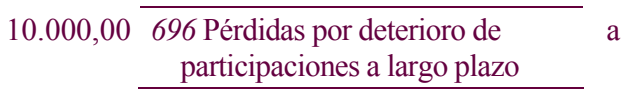

$250 \mathrm{IF}$ a l. p. en instrumentos de
patrimonio
$10.000,00$

En consecuencia, en el activo del balance figurará la cuenta de "Inversiones financieras a largo plazo en instrumentos de patrimonio" con un saldo de $20.000 €$.

b) Considerar la diferencia negativa al cierre del ejercicio X1 como deterioro de valor. En este caso, en primer lugar se trasladarán los ajustes positivos registrados en el patrimonio neto al cierre del ejercicio X (20.000) a resultados y la diferencia negativa (50.000) se contabilizará como deterioro:

\begin{tabular}{|c|c|c|c|c|}
\hline & & & & \\
\hline $20.000,00$ & $\begin{array}{l}802 \text { Transferencias de beneficios } \\
\text { en activos financieros } \\
\text { disponibles para la venta }\end{array}$ & $\mathrm{a}$ & $\begin{array}{l}7632 \text { Beneficios por valoración de } \\
\text { instrumentos fin. por su valor } \\
\text { razonable. De disponibles para } \\
\text { venta }\end{array}$ & $20.000,00$ \\
\hline $20.000,00$ & $\begin{array}{l}133 \text { Ajustes por valoración en } \\
\text { activos financieros disponibles } \\
\text { para la venta }\end{array}$ & $\mathrm{a}$ & $\begin{array}{l}802 \text { Transferencias de beneficios } \\
\text { en activos financieros } \\
\text { disponibles para la venta }\end{array}$ & $20.000,00$ \\
\hline $50.000,00$ & $\begin{array}{l}696 \text { Pérdidas por deterioro de } \\
\text { participaciones a largo plazo }\end{array}$ & $\mathrm{a}$ & $\begin{array}{l}250 \mathrm{IF} \text { a l.p. en instrumentos de } \\
\text { patrimonio }\end{array}$ & $50.000,00$ \\
\hline
\end{tabular}

En el activo del balance a 31-12-X1 figurará la cuenta de "Inversiones Financieras a largo plazo en Instrumentos de Patrimonio" con saldo de $30.000 €$.

Ejercicio X2:

Si en este ejercicio, como se indica anteriormente, la cotización de los títulos hubiera continuado descendiendo, por ejemplo a $2 € /$ acción, se debe contabilizar la nueva pérdida como deterioro:
$10.000,00 \quad 696$ Pérdidas por deterioro de participaciones a largo plazo

250 IF a l.p. en instrumentos de patrimonio

$10.000,00$

En el caso de instrumentos de patrimonio que se valoren por su coste, por no poder determinarse con fiabilidad su valor razonable (acciones no cotizadas), la corrección valorativa por deterioro se determinará de acuerdo con los criterios establecidos en la misma norma de registro y valoración $n^{\circ} 9$ para las inversiones en el patrimonio en

3 Como se trata de participaciones en empresas que no son del grupo o asociadas la contabilización del deterioro se lleva directamente contra la cuenta representativa de las participaciones. En caso contrario, es decir, si se trata de participaciones en partes vinculadas se deberá utilizar como contrapartida de la pérdida por deterioro la cuenta correctora de valor correspondiente que dependiendo del plazo será: "293. Deterioro de valor de participaciones a largo plazo en partes vinculadas", ó "593. Deterioro de valor de participaciones a corto plazo en partes vinculadas". 
empresas del grupo, multigrupo y asociadas, es decir, se seguirá el siguiente procedimiento:

a) El deterioro se calculará por diferencia entre el valor en libros y el importe recuperable.

b) Importe recuperable: valor razonable (menos gastos de venta) o valor actual de los flujos de efectivo derivados de la inversión, el mayor.

c) Cálculo de los flujos de efectivo:

- estimación de lo que se espera recibir como consecuencia del reparto de dividendos por la entidad emisora (empresa participada) y de la enajenación de los activos.

- estimación de su participación en los flujos que se espera sean generados por la empresa participada, procedentes tanto de sus actividades ordinarias como de su enajenación.

No obstante, y para paliar la aparente complejidad que supone este proceso, la norma añade que, salvo mejor evidencia del importe recuperable, en la estimación del deterioro de esta clase de inversiones se tomará en consideración el patrimonio neto de la entidad participada corregido por las plusvalías tácitas existentes en la fecha de la valoración; es decir, el deterioro se determinará a partir del valor teórico de las acciones tal y como se recoge en el ya derogado PGC de 1990, tanto para las participaciones en empresas del grupo o asociadas como para las participaciones en capital no admitidas a cotización.

\section{Ejemplo n ${ }^{0}$ 5.-}

Una empresa posee 2.975 acciones de la sociedad anónima "ALFA" adquiridas, durante el ejercicio $X$ al precio de $6 € /$ acción, clasificando dicha inversión como disponibles para la venta. Dichos títulos no están admitidos a cotización en ningún mercado oficial. Para el cálculo del posible deterioro de estos títulos, se sabe que capital de "ALFA, S.A." se compone de 42.500 acciones y el valor de su patrimonio neto es (no existen plusvalías tácitas):
a) A 31-12-X: $148.750 €$
b) A 31-12-X1: $193.200 €$

Solución.-

Inicialmente estos títulos se valorarán a su precio de coste: $2.975 \times 6=17.850$. 
Posteriormente, estos títulos como no disponen de un valor de mercado fiable, se seguirán valorando al coste, pero al cierre de ejercicio deben ser objeto de correcciones valorativas si se observa evidencia de deterioro. En este caso, el valor teórico de las acciones "ALFA" (148.750/42.500) es de 3,5€ que está muy por debajo de los $6 €$ del precio de coste. Por tanto la corrección valorativa por deterioro se calculará:

\begin{tabular}{|c|c|}
\hline 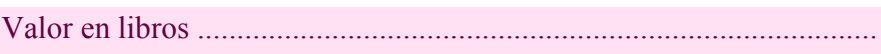 & $17.850,00$ \\
\hline Valor recuperable (patrimonio neto) $3,5 \times 2.975$ & $10.412,50$ \\
\hline Pérdida por deterioro $(31-12-\mathrm{X})$........................... & $7.437,50$ \\
\hline
\end{tabular}

La anotación contable correspondiente será:

$7.437,50696$ Pérdidas por deterioro de participaciones a largo plazo

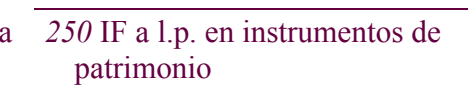

$7.437,50$

En el ejercicio X1, el valor teórico de las acciones "ALFA" ha subido a (193.200/42.500) 4,55€, pero tal y como establece la norma no es posible la reversión de la corrección valorativa.

\subsection{Reclasificación de inversiones financieras}

En el apartado 2.7 de la norma de registro y valoración $n^{\circ} 9$ del nuevo PGC se establece que no se podrá reclasificar ningún activo financiero incluido inicialmente en la categoría de mantenidos para negociar a otras categorías, ni de éstas a aquélla, salvo cuando proceda calificar al activo como inversión en el patrimonio de empresas del grupo, multigrupo o asociadas. Por tanto, la clasificación de un instrumento financiero dentro de esta categoría es irrevocable $y$, asimismo, ningún instrumento financiero que pertenezca a las restantes categorías puede ser reclasificado dentro de esta categoría ${ }^{4}$.

4 El 13 de octubre de 2008, el Consejo de Normas Internacionales de Contabilidad (ISAB) aprobó una serie de modificaciones de la NIC 39 y de la NIIF 7 que permiten, en circunstancias excepcionales, reclasificar determinados instrumentos financieros, detrayéndolos de la categoría de "mantenidos para negociar". Cabe considerar que la actual crisis financiera constituye una circunstancia excepcional que justifica el recurso a tal posibilidad por parte de las empresas.

De la misma forma, el 15 de octubre de 2008 se aprueba el Reglamento (CE) N ${ }^{\circ}$ 1004/2008 de la Comisión que incorpora a la legislación europea las citadas modificaciones. Como se recordará, las Normas Internacionales de Contabilidad del ISAB fueron adoptadas por la Unión Europea en virtud del Reglamento (CE) n 1606/2002 siendo de aplicación obligatoria para los grupos consolidados admitidos a cotización.

En síntesis, las modificaciones de la NIC 39 y de la NIIF 7 establecen que cuando se reclasifique un activo financiero que inicialmente fue clasificado como "activo para negociar", no se revertirá ninguna pérdida o ganancia ya reconocida en resultados. El valor razonable del activo financiero en la fecha de reclasificación pasará a ser su nuevo coste (instrumentos de patrimonio) o coste amortizado (valores representativos de deudas), según proceda Asimismo, se deberá dar amplia información del importe reclasificado, de la situación excepcional y de los hechos y circunstancias que demuestren que la situación era excepcional. 
Con relación a la cartera de inversiones mantenidas hasta el vencimiento, ya se comentó en el apartado 4.1.1, que no se podrá clasificar ningún activo en esta cartera si en el ejercicio actual o en los dos precedentes, se han vendido o reclasificado activos incluidos en esta categoría por importe relevante, salvo que se trate de alguno de los tres supuestos indicados (ventas o reclasificaciones muy próximas al vencimiento, que hayan ocurrido cuando se haya cobrado la práctica totalidad del principal, o atribuibles a un suceso aislado, no recurrente y fuera del control de la empresa).

Si debido a un cambio en la intención o capacidad financiera de la empresa no es apropiado mantener los activos en la cartera de inversión a vencimiento, o a consecuencia de una venta o reclasificación por importe significativo, dichos activos, y los demás que queden en esta cartera, tendrán que ser reclasificados a la cartera de disponibles para la venta. La diferencia entre el coste amortizado (criterio de valoración empleado en la cartera de inversiones mantenidas hasta el vencimiento) y el valor razonable (criterio de valoración empleado en la cartera de disponibles para la venta) en el momento de la reclasificación se reflejará en el patrimonio neto.

Si como resultado de un cambio en la intención o en la capacidad financiera de la empresa o, pasados dos ejercicios desde la reclasificación de la cartera de inversión a vencimiento a la de disponibles para la venta, se decide de nuevo reclasificar los activos financieros que se tengan disponibles para la venta como inversión mantenida hasta vencimiento, el valor razonable en el momento de la reclasificación será el nuevo coste amortizado y a partir de ahí dichos activos se valorarán al coste amortizado de forma que las ganancias o pérdidas registradas previamente en el patrimonio neto se mantendrán en éste y se amortizarán, es decir, se imputarán a resultados durante la vida residual del activo financiero utilizando el método del tipo de interés efectivo.

\section{Ejemplo n ${ }^{0}$ 6.-}

Partiendo de los mismos datos del Ejemplo 1, supóngase que con fecha 31-12-X2, la empresa propietaria de los bonos decide reclasificarlos dentro de la cartera de disponibles para la venta debido a un cambio respecto a su intención de seguir manteniéndolos hasta el vencimiento. En el momento de la reclasificación, el valor de los bonos en el mercado después del obro del cupón es de $9.700 €$. 


\section{Solución.-}

Para llevar a cabo la reclasificación indicada, la empresa deberá considerar la diferencia entre el coste amortizado de los bonos en dicha fecha que asciende a 9.516,68 (véase cuadro del Ejemplo 1) y el valor razonable de la inversión en ese momento (9.700) y asignar esa diferencia $(183,32)$ a una cuenta de patrimonio neto. Es decir, procedería realizar los siguientes asientos:

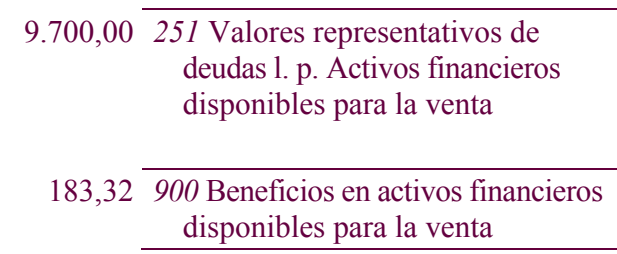

251 Valores represent. Deudas 1.p. Inversiones mantenidas hasta vto.

a 900 Beneficios en activos financieros disponibles para la venta

a 133 Ajustes por valoración en activos financ. disponibles para la vta.
$9.516,68$

183,32

\section{Ejemplo n ${ }^{0}$ 7.-}

La sociedad anónima "RIOSOL" adquirió el 1 de enero del año X, 1.000 bonos de $100 €$ de valor nominal cada uno de la entidad BB por un precio total de $95.000 €$ y con un plazo de 5 años. Dichos títulos devengan un cupón anual del 5\% que se paga cada 31 de diciembre hasta vencimiento. El reembolso se efectuará por su valor nominal. El 1 de enero del año siguiente (X1) la sociedad vende 500 bonos lo que obliga a la empresa a reclasificar el resto de los bonos a la cartera de disponibles para la venta. No obstante, la sociedad tiene la intención de conservar el resto de esta inversión hasta la fecha de su reembolso, por lo que transcurridos dos años de esta reclasificación la sociedad vuelve a traspasar los bonos a la cartera de mantenidos hasta vencimiento. El valor de mercado de los bonos en las fechas de mercado correspondientes es el siguiente:

$$
\begin{array}{ll}
\text { 1-1-X1: } & \text { 97€/titulo } \\
\text { 31-12-X1: } & \text { 105€/titulo } \\
\text { 31-12-X2: } & \text { 103€/titulo }
\end{array}
$$

\section{Solución.-}

La adquisición de los títulos y su clasificación como inversión a vencimiento exige como paso previo a su contabilización el cálculo del tipo de interés efectivo (TIE) y el cuadro de amortización hasta la fecha de reembolso:

$$
95.000=\frac{5.000}{(1+i)^{1}}+\frac{5.000}{(1+i)^{2}}+\frac{5.000}{(1+i)^{3}}+\frac{5.000}{(1+i)^{4}}+\frac{105.000}{(1+i)^{5}} \quad \text { TIE }=6,193 \%
$$

Cuadro de amortización 1:

\begin{tabular}{|c|c|c|c|c|}
\hline Fecha & Intereses & Cobros & Diferencia & Coste amortizado \\
\hline $1-1-\mathrm{X}$ & & & & 95.000 \\
\hline $31-12-\mathrm{X}$ & $5.883,57$ & 5.000 & 883,57 & $95.883,57$ \\
\hline $31-12-\mathrm{X} 1$ & $5.938,29$ & 5.000 & 938,29 & $96.821,86$ \\
\hline $31-12-\mathrm{X} 2$ & $5.996,40$ & 5.000 & 996,40 & $97.818,26$ \\
\hline $31-12-\mathrm{X} 3$ & $6.058,10$ & 5.000 & $1.058,10$ & $98.876,36$ \\
\hline $31-12-\mathrm{X} 4$ & $6.123,64$ & 105.000 & $(98.876,36)$ & 0 \\
\hline
\end{tabular}


El registro contable de las operaciones correspondientes a la citada inversión en cada fecha será la siguiente:

1-1-X: adquisición de los valores:

\begin{tabular}{cccc}
$95.000,00$ & $\begin{array}{l}\text { 251 Valores represent. deudas } \\
\text { l.p. Inversiones mantenidas } \\
\text { hasta vto. }\end{array}$ & $55.000,00$ \\
\hline
\end{tabular}

31-12-X: periodificación intereses (explícitos e implícitos) y cobro del cupón:

\begin{tabular}{cc}
$5.000,00$ & $\begin{array}{l}546 \text { Intereses c.p. de valores } \\
\text { representativos de deudas }\end{array}$ \\
883,57 & $\begin{array}{c}\text { 251 Valores represent. deudas } \\
\text { l.p. Inversiones mantenidas } \\
\text { hasta vto. }\end{array}$ \\
\cline { 2 - 2 } $5.000,00$ & $\begin{array}{l}57 \text { Tesorería (para mayor } \\
\text { simplicidad se prescinde de la } \\
\text { retención fiscal) }\end{array}$ \\
\hline
\end{tabular}

761 Ingresos de valores representativos de deudas

$5.883,57$
546 Intereses c.p. de valores representativos de deudas

1-1-X1: venta de 500 bonos y reclasificación del resto a la cartera de disponibles para la venta:

$$
\begin{array}{cc}
48.500,00 & 57 \text { Tesorería } \\
\end{array}
$$

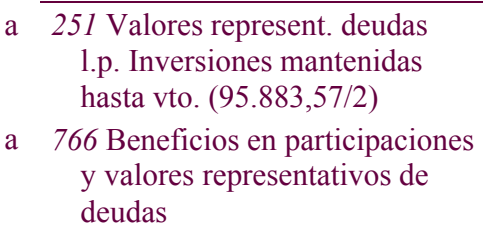

El resto de los títulos al reclasificarse en la cartera de disponibles para la venta se valoran a valor razonable, esto es, a su precio de mercado $(500 \times 97 €)$ y la diferencia con su coste amortizado $(47.941,78)$ se llevará a patrimonio neto:

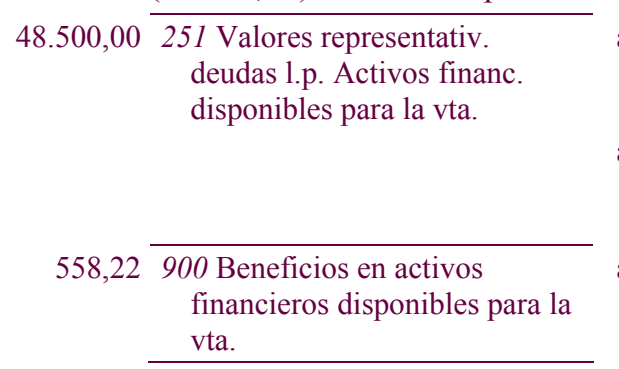

251 Valores represent. deudas hasta vto.

a 900 Beneficios en activos financieros disponibles para la vta.

a 133 Ajustes por valoración en
activos financieros disp. para
la vta.

31-12-X1: periodificación intereses, cobro del cupón y ajuste a valor de mercado (105€):

Con el fin de conocer los intereses devengados por los títulos que permanecen en cartera sería conveniente hacer un nuevo cuadro de amortización para los mismos (se mantiene el mismo TIE) aunque en este ejemplo, se pueden deducir fácilmente del anterior por tratarse de la mitad de la inversión inicial.

$$
\mathrm{TIE}=6,193 \%
$$

Cuadro de amortización 2 (500 títulos): 


\begin{tabular}{|c|c|c|c|c|}
\hline Fecha & Intereses & Cobros & Diferencia & Coste amortizado \\
\hline $1-1-\mathrm{X}$ & & & & 47.500 \\
\hline $31-12-\mathrm{X}$ & $2.941,78$ & 2.500 & 441,78 & $47.941,78$ \\
\hline $31-12-\mathrm{X} 1$ & $2.969,14$ & 2.500 & 469,14 & $48.410,92$ \\
\hline $31-12-\mathrm{X} 2$ & $2.998,20$ & 2.500 & 498,20 & $48.909,12$ \\
\hline $31-12-\mathrm{X} 3$ & $3.029,06$ & 2.500 & 529,06 & $49.438,18$ \\
\hline $31-12-\mathrm{X} 4$ & $3.061,83$ & 52.500 & $(49.438,18)$ & 0 \\
\hline
\end{tabular}

2.500,00 546 Intereses c.p. de valores representativos de deudas a 761 Ingresos de valores representativos de deudas

$2.969,14$

469,14 251 Valores represent. deudas 1. p. Activos financ. disponibles para vta.

$2.500,00 \quad 57$ Tesorería (para mayor simplicidad se prescinde de la retención fiscal)

Valor contable a 31-12-X1: $48.500+469,14$

$3.530,86 \quad 251$ Valores represent. deudas 1.p a Activos financ. disponibles para la vta.

$3.530,86900$ Beneficios en activos financieros disponibles para la vta.
900 Beneficios en activos financ. disponibles para la vta.

a 133 Ajustes por valoración en activos financieros disp. para la vta.

31-12-X2: periodificación intereses, cobro del cupón y ajuste a valor de mercado (103€):

\begin{tabular}{cc}
$2.500,00$ & $\begin{array}{c}546 \text { Intereses c.p. de valores } \\
\text { representativos de deudas }\end{array}$ \\
498,20 & $\begin{array}{r}251 \text { Valores represent. deudas 1.p } \\
\text { Activos financ. disponibles } \\
\text { para la vta. }\end{array}$ \\
\cline { 2 - 2 } $2.500,00$ & $\begin{array}{l}57 \text { Tesorería (para mayor } \\
\text { simplicidad se prescinde de la } \\
\text { retención fiscal) }\end{array}$ \\
\hline
\end{tabular}

a 761 Ingresos de valores representativos de deudas

Valor contable a 31-12-X2: $52.500+498,20$

Valor razonable a 31-12-X2: 500×103

Diferencia negativa

\subsection{8,20 800 Pérdidas en activos financieros disponibles para la vta.}

1.498,20 133 Ajustes por valoración en activos financieros disponibles para la vta. a 251 Valores represent. deudas 1.p

Activos financ. disponibles para la vta.

a 800 Pérdidas en activos financieros disponibles para la vta. 
1-1-X3: reclasificación de disponibles para la venta a mantenidas a vto.

En el momento de esta nueva reclasificación el coste amortizado de los títulos es de $48.909,12 €$ y su valor de mercado de 51.500€. Por tanto, en el patrimonio neto habrá acumulada una diferencia positiva de 2.590,88 $(51.500-48.909,12)$ que, efectivamente, coincide con el saldo acreedor de la cuenta "133. Ajustes por valoración en activos financieros disponibles para la venta".

Por otro lado, el valor contable de la inversión en esa fecha (51.500) se convierte en el nuevo coste amortizado que habrá que periodificar hasta el vencimiento calculando un nuevo tipo de interés efectivo para el tiempo que resta de la inversión. El nuevo TIE se calculará a partir de la siguiente expresión:

$$
51.500=\frac{2.500}{(1+i)^{1}}+\frac{52.500}{(1+i)^{2}} \quad \text { TIE }=3,422 \%
$$

El nuevo cuadro de amortización para los dos años que faltan es el siguiente:

Cuadro de amortización 3:

\begin{tabular}{|c|c|c|c|c|}
\hline Fecha & Intereses & Cobros & Diferencia & Coste amortizado \\
\hline $31-12-\mathrm{X} 3$ & & & & 51.500 \\
\hline $31-12-\mathrm{X} 4$ & $1.762,62$ & 2.500 & $(737,38)$ & $50.762,62$ \\
\hline $31-12-\mathrm{X} 5$ & $1.737,38$ & 52.500 & $(50.762,62)$ & 0 \\
\hline
\end{tabular}

El importe que antes de esta última reclasificación figura en cuenta de patrimonio neto $(2.590,88)$, deberá imputarse a resultados durante los dos años restantes de la forma siguiente:

- Año X3: se traspasará a resultados $1.266,44$ que se obtiene por diferencia entre los intereses devengados en el cuadro de amortización 2 y los devengados según el nuevo TIE (cuadro de amortización 3) (3.029,06-1.762,62).

- Año X4: se traspasará a resultados 1.324,45, diferencia entre 3.061,83 y 1.737,38.

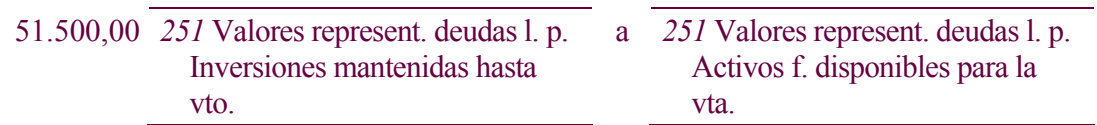
$51.500,00$

31-12-X3: periodificación intereses, cobro del cupón, imputación a resultados del saldo de patrimonio neto y reclasificación inversión a corto plazo:

\begin{tabular}{|c|c|c|c|c|}
\hline \multirow{3}{*}{$2.500,00$} & \multirow{3}{*}{$\begin{array}{l}546 \text { Intereses c.p. de valores } \\
\text { representativos de deudas }\end{array}$} & \multirow{3}{*}{$\begin{array}{l}\mathrm{a} \\
\mathrm{a}\end{array}$} & & \\
\hline & & & 761 Ingresos valores repr. deud. & $1.762,62$ \\
\hline & & & $\begin{array}{l}251 \text { Valores represent. deu. 1.p. } \\
\text { Inversiones mantenidas hasta } \\
\text { vto. }\end{array}$ & 737,38 \\
\hline $2.500,00$ & 57 Tesorería & $\mathrm{a}$ & $\begin{array}{l}546 \text { Intereses c.p. de valores } \\
\text { representativos de deuda }\end{array}$ & $2.500,00$ \\
\hline $1.266,44$ & $\begin{array}{l}802 \text { Transferencia de beneficios } \\
\text { en activos financieros } \\
\text { disponibles para la vta. }\end{array}$ & $\mathrm{a}$ & $\begin{array}{l}763 \text { Beneficios por valoración de } \\
\text { instrumentos financieros por su } \\
\text { valor razonable }\end{array}$ & $1.266,44$ \\
\hline $1.266,44$ & $\begin{array}{l}133 \text { Ajustes por valoración en } \\
\text { activos financieros disponibles } \\
\text { para la vta. }\end{array}$ & $\mathrm{a}$ & $\begin{array}{l}802 \text { Transferencia de beneficios } \\
\text { en activos financieros } \\
\text { disponibles para la vta. }\end{array}$ & $1.266,44$ \\
\hline
\end{tabular}



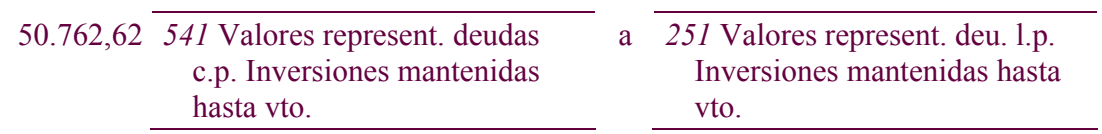
$50.762,62$

31-12-X4: periodificación intereses, cobro del cupón, imputación a resultados del saldo de patrimonio neto y amortización de la inversión:

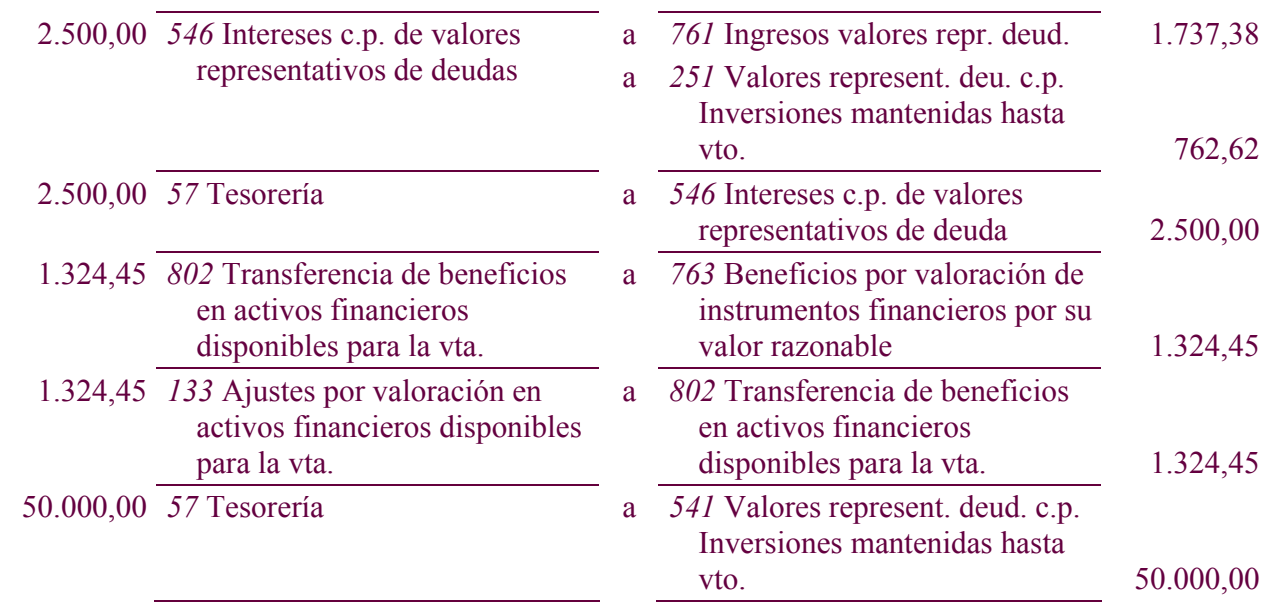

\subsection{Baja de inversiones financieras}

La norma de registro y valoración $n^{\circ} 9$ recoge una amplia regulación relativa a la baja en balance de los activos financieros que, en síntesis, se producirá cuando expiren o se hayan cedido los derechos contractuales sobre los flujos de efectivo de los activos financieros, siendo necesario que se hayan transferido de manera sustancial los riesgos y beneficios inherentes a su propiedad. No cabe duda de que tratándose de inversiones financieras propiamente dichas, esta baja se produce en los casos de venta incondicional o cuando llegue el vencimiento de un título de deuda.

De esta forma, si una entidad transfiere los derechos sobre una inversión financiera deberá darla de baja en sus cuentas, reconociendo los beneficios o pérdidas derivadas de la transacción por diferencia entre el importe recibido y su valor contable. Si el activo en cuestión forma parte de la cartera de disponibles para la venta será preciso trasladar a resultados la parte proporcional del saldo que presente la cuenta "133. Ajustes por valoración en activos financieros disponibles para la venta", ya que entonces las ganancias o pérdidas recogidas en dicha cuenta se pueden considerar como realizadas. 
El problema se plantea cuando no resulta claro si se han cedido los derechos contractuales a recibir los flujos de efectivo derivados del activo financiero, en cuyo caso será necesario evaluar en qué medida la entidad retiene los riesgos y beneficios inherentes a la propiedad de los mismos y se darán de baja en caso de que no los haya retenido.

Se entenderá que se han transferido de manera sustancial los riesgos y beneficios inherentes a la propiedad de los activos cuando la exposición de la empresa a la variación en los flujos de efectivo del activo transferido deje de ser significativa en relación con la variación total del valor actual de los flujos de efectivo futuros netos asociados con el activo financiero.

Para aquellos casos en los que la entidad no transfiere ni retiene de manera sustancial los riesgos y ventajas inherentes a la propiedad de los activos financieros, se deberá determinar si todavía conserva el control de los mismos y se deberán dar de baja cuando se haya perdido dicho control. Si la empresa cedente mantiene el control del activo continuará reconociéndolo en la medida de su implicación continuada, lo que puede dar lugar a una baja parcial del valor.

Con todo este proceso, lo que se pretende es aclarar si la transacción realizada con el activo financiero constituye una cesión total de los riesgos y ventajas que se derivan del mismo y si, en consecuencia, los flujos de caja que originan pueden afectar a la empresa. La baja se produce, cuando estos flujos futuros no tienen efecto sobre la empresa, es decir, cuando las alteraciones de los flujos no generen beneficios ni pérdidas para la empresa.

Con relación a la implicación continuada a que se refiere al párrafo anterior, se produce cuando, por ejemplo, la empresa vende unas inversiones financieras con la obligación de recomprarlas transcurrido un plazo por un precio fijo establecido previamente en el contrato de venta (ventas con pacto de recompra). Esta operación constituye claramente una operación de financiación para la entidad vendedora en la que los títulos transferidos constituyen una garantía para el préstamo obtenido. Dada la prevalencia del fondo económico sobre la forma jurídica de las operaciones, la empresa no dará de baja los valores aunque desde un punto de vista legal no sea la propietaria, ya que continua implicada en los flujos de efectivo de forma absoluta, debiendo reconocer un pasivo por la cantidad recibida por la venta. 


\section{LAS INVERSIONES FINANCIERAS EN EL PGC DE PEQUEÑAS Y MEDIANAS EMPRESAS}

El PGC de PYMES constituye el desarrollo de las normas contables que pueden ser aplicadas, de forma voluntaria, por las empresas que cumplan las condiciones establecidas en el artículo 175 del Texto Refundido de la Ley de Sociedades Anónimas, para la formulación de balance y estado de cambios en el patrimonio neto abreviados, es decir, este nuevo texto normativo podrán aplicarlo todas las empresas, cualquiera que sea su forma jurídica, individual o societaria que, durante dos ejercicios consecutivos, reúnan a la fecha de cierre al menos dos de las tres circunstancias siguientes:

a) Que el total de las partidas del activo del balance no supere los 2.850.000€,

b) Que el importe neto de la cifra de negocios no supere los 5.700.000€,

c) Que el número medio de trabajadores empleados no sea superior a 50 .

Asimismo, se exige que las empresas que quieran aplicar este Plan no se encuentren en alguna de las siguientes circunstancias:

a) Que tengan valores admitidos a negociación en un mercado regulado de cualquier Estado miembro de la Unión Europea.

b) Que formen parte de un grupo de sociedades que formule o debiera haber formulado cuentas anuales consolidadas.

c) Que su moneda funcional sea distinta del euro.

d) Que se trate de entidades financieras para las que existan disposiciones específicas en materia contable.

La opción que una empresa ejerza de seguir el Plan de las PYMES o el General deberá mantenerse de forma continuada, como mínimo, durante tres ejercicios, salvo que, con anterioridad al transcurso de dicho plazo, la empresa pierda la facultad de aplicar el PGC de PYMES al no cumplir los requisitos anteriores.

Cuando una empresa opte por aplicar el Plan de las PYMES deberá hacerlo de forma completa. No obstante, no tiene carácter vinculante la cuarta y quinta parte. En consecuencia, se prohíbe la aplicación parcial del PGC de PYMES, ya que se deberá considerar como 
un cuerpo completo sin perjuicio de que cuando se realicen operaciones cuyo tratamiento contable no esté contemplado en el Plan de las PYMES, habrá que remitirse a lo regulado en el Plan General de Contabilidad, con la excepción de las normas relativas a activos no corrientes y grupos enajenables de elementos mantenidos para la venta, que en ningún caso serán aplicables.

Este texto normativo se caracteriza porque, si bien mantiene la misma estructura del Plan General, presenta una simplificación importante con relación a ciertos criterios de registro y valoración, de forma que en la segunda parte del Plan se han eliminado o simplificado normas que regulan operaciones o transacciones que habitualmente no realizan estas empresas. Así por ejemplo, se han eliminado las normas o apartados que afectan a: fondo de comercio, instrumentos financieros compuestos, coberturas contables, activos no corrientes y grupos enajenables de elementos mantenidos para la venta, pasivos por retribuciones al personal, transacciones con pagos en instrumentos de patrimonio, combinaciones de negocios, operaciones de fusión, escisión y aportaciones no dinerarias de un negocio entre empresas del grupo.

Con relación al tema que nos ocupa, conviene destacar que se han simplificado algunos de los criterios y normas recogidos en la norma de registro y valoración $n^{\circ} 9$ Instrumentos financieros del PGC; en particular se han eliminado ciertas categorías de activos financieros y se ha suprimido el criterio de valoración a valor razonable con cambios de valor a patrimonio neto.

De esta forma, y al objeto de facilitar la comprensión de toda la operatoria contable que se deriva de los instrumentos financieros, la citada norma de valoración $\mathrm{n}^{\circ} 9$ se ha desglosado en el Plan de las PYMES en las cuatro siguientes:

Norma $8^{\text {a }}$ Activos Financieros

Norma $9^{a}$ Pasivos Financieros

Norma $10^{\text {a }}$ Contratos Financieros Particulares

Norma $11^{\text {a }}$ Instrumentos de patrimonio propios

Dado el objetivo de nuestro tema, nos centraremos en comentar la norma $n^{\circ} 8$ en la que se regulan todos los activos financieros definidos de igual forma y con las mismas categorías que en el PGC. Así, y a efectos de su valoración, una empresa que aplique el Plan de las PYMES clasificará sus activos financieros en alguna de las tres categorías siguientes: 
1. Activos financieros a coste amortizado.

2. Activos financieros mantenidos para negociar.

3. Activos financieros a coste.

\subsection{Activos financieros a coste amortizado}

Se incluirán en esta categoría, además de todos los créditos por operaciones comerciales, todos aquellos activos financieros que, no siendo instrumentos de patrimonio ni derivados, no tienen origen comercial y cuyos cobros son de cuantía determinada o determinable; es decir, tratándose de inversiones financieras, comprenderá los valores representativas de deuda, ya sean cotizados o no.

La valoración inicial de estas inversiones se realizará por el coste, esto es, el valor razonable de la contraprestación entregada más los costes de transacción que les sean directamente imputables. No obstante, y con el fin de facilitar el cálculo del coste amortizado (criterio de valoración posterior), estos costes de transacción pueden registrarse, si se desea, directamente en la cuenta de pérdidas y ganancias en el momento de su valoración. Sin embargo, tal vez es más conveniente utilizar el criterio del PGC e incluir estos gastos en la valoración inicial ya que de esta forma influyen en el cálculo del tipo de interés efectivo, el cuál nos permite conocer la rentabilidad real de la inversión realizada, rentabilidad que depende de estos gastos y de los tipos de interés tanto explícitos como implícitos.

Al igual que sucede en el PGC, en esta valoración inicial debe tenerse en cuenta el importe de los interese explícitos devengados no vencidos (cupón corrido), los cuales se registrarán de forma independiente atendiendo a su vencimiento.

La valoración posterior de los valores representativos de deuda asignados a esta categoría se efectuará por su coste amortizado, imputando a la cuenta de pérdidas y ganancias los intereses devengados mediante el método del tipo de interés efectivo.

Asimismo, al menos al cierre de ejercicio, deberán efectuarse las necesarias correcciones valorativas si se comprueba que existe evidencia objetiva de que el valor de estos activos se ha deteriorado. Dicho deterioro se debe estimar si se considera que puede producirse una reducción o retraso en los flujos de efectivo futuros, motivados por la insolvencia del deudor. Las correcciones valorativas por deterioro, así 
como su posible reversión, se reconocerán como un gasto o un ingreso, respectivamente, en la cuenta de pérdidas y ganancias.

Como puede observarse, el tratamiento previsto en el Plan de las PYMES para estas inversiones es el mismo que se establece en el PGC para los títulos asignados a la cartera de inversiones mantenidas hasta vencimiento, con la única diferencia de que, en este caso, no existe ninguna limitación para su venta, pudiéndose enajenar cuando la empresa lo desee sin necesidad de mantenerlos hasta la fecha de su amortización.

\subsection{Activos financieros mantenidos para negociar}

Esta cartera se mantiene con los mismos criterios que en el PGC por lo que nos remitimos a los comentarios realizados en el apartado 4.2.

\subsection{Activos financieros a coste}

En esta categoría se clasificarán las inversiones en el patrimonio de empresas del grupo, multigrupo y asociadas y los demás instrumentos de patrimonio que no sean clasificados como activos para negociar.

La valoración inicial de estas inversiones se realizará, como en casos anteriores, por el coste, que equivaldrá al valor razonable de la contraprestación entregada más los costes de transacción que les sean directamente atribuibles, debiéndose tener en cuenta, igualmente, los derechos preferentes de suscripción y similares que formarán parte del valor inicial y el importe de los dividendos acordados antes de la adquisición que se contabilizará de forma independiente.

Con posterioridad, los títulos incluidos en esta categoría se seguirán valorando al coste menos, en su caso, el importe acumulado de las correcciones valorativas por deterioro; es decir, se mantiene el mismo criterio de valoración que en el derogado Plan del 90.

En consecuencia, al menos al cierre del ejercicio se deberán efectuar las necesarias correcciones valorativas si existe evidencia objetiva de que el valor en libros de una inversión no será recuperable.

El importe de dicha corrección valorativa se determinará siguiendo el mismo procedimiento que se ha explicado en el apartado 4.3.3 al referirnos a los instrumentos financieros incluidos en la categoría de 
disponibles para la venta para los que no se dispone de un valor razonable fiable. Dicho procedimiento se puede resumir de la forma siguiente:

a) En el caso de participaciones en el patrimonio de empresas del grupo, multigrupo o asociadas, la corrección valorativa será la diferencia entre el valor en libros y el importe recuperable. No obstante, como se recordará, salvo mejor evidencia de este importe, en la estimación del deterioro se tomará en consideración el patrimonio neto de la sociedad participada corregido por las plusvalías tácitas existentes en el momento de la valoración.

b) Cuando se trate de participaciones en el patrimonio de empresas que no sean del grupo, multigrupo o asociadas, pero sean títulos que han sido admitidos a negociación en mercados oficiales, el deterioro se determinará comparando su valor en libros con su valor de cotización, siempre que éste sea lo suficientemente fiable como para considerarlo representativo del valor que pudiera recuperar la empresa.

c) Tratándose de inversiones no admitidas a cotización, el deterioro se calculará como en el apartado a), es decir, teniendo en cuenta el patrimonio neto de la sociedad participada que nos permitirá comparar el valor en libros de la inversión con su valor teórico contable.

Como puede observarse, en este caso los cambios con relación al Plan de 1990 son mínimos, ya que una PYME que adquiera acciones o participaciones en el patrimonio neto y no desee clasificarlas como activos mantenidos para negociar, las valorará al precio de coste, ajustado al valor de mercado o al valor teórico, si es menor.

En síntesis, una empresa que pueda y quiera aplicar el Plan de las PYMES, si adquiere títulos representativos de deuda y no desea mantenerlos para negociar los valorará a coste amortizado, y si se trata de valores de renta variable que tampoco quiere asignar la cartera de negociación los valorará a coste, siendo necesario, en ambos casos, efectuar las correcciones valorativas pertinentes en el supuesto de que exista evidencia objetiva de deterioro. 
Ejemplo n ${ }^{0}$ 8.-

La empresa "H" aplica el Plan General de Contabilidad de PYMES al cumplir los requisitos establecidos en el Real Decreto 1515/2007, por el que se aprueba dicho texto contable. Durante el ejercicio $X$ ha realizado las siguientes inversiones financieras:

a) El día 1-7-X (fecha de emisión de obligaciones REPSA) compra 3.000 títulos de $10 €$ de valor nominal, con un interés explícito del 4\% que se cobrará anualmente, estableciéndose su plazo de amortización a los dos años por el mismo valor nominal. Los gastos de comisión bancaria ascienden a 150€. Dado que, en principio, la empresa no tiene claras sus intenciones con relación a esta inversión decide clasificarla como activos financieros a coste amortizado.

b) Con fecha 13-10-X compra en Bolsa, con la intención de negociar, 200 acciones de la misma sociedad REPSA de $60 €$ de valor nominal a una cotización del $230 \%$ y gastos de intermediación de $85 €$. Con anterioridad a dicha adquisición, se había anunciado por parte del consejo de Administración de REPSA el pago de un dividendo a cuenta de 0,5€ por acción que se cobra el día 20-10-X.

c) Por último, el día 22-11-X compra a la sociedad REPOSA, cuyos títulos no están admitidos a cotización en ningún mercado oficial, 1.000 acciones por un precio total de 35.500€. El Capital social de dicha sociedad está constituido por 50.000 acciones de $30 €$ de valor nominal.

Al cierre del ejercicio $X$ el valor de las citadas inversiones es el siguiente:

- Las obligaciones REPSA tienen un valor de mercado de 12€/título.

- Las acciones REPSA cotizan al 205\%.

- El patrimonio neto de REPOSA, como consecuencia de las importantes pérdidas que ha sufrido la sociedad en el último año, es de 1.100.000€.

\section{Solución.-}

El registro contable de las operaciones correspondientes a las inversiones financieras realizadas por la empresa " $\mathrm{H}$ " durante el ejercicio X es el siguiente:

\section{a) Obligaciones REPSA:}

Valoración por el coste amortizado, por tanto habrá que calcular el TIE y el cuadro de amortización de los títulos. No obstante, la empresa decide registrar los costes de transacción directamente en la cuenta de pérdidas y ganancias, con lo que, en este caso, coincide el valor inicial de la inversión con su valor de reembolso. En consecuencia el TIE coincidirá con el interés explícito; esto es:

\begin{tabular}{|c|c|}
\hline Valor inicial de la inversión: $3.000 \times 10$ & $30.000,00$ \\
\hline Importe cupón anual: $30.000 \times 0,04$ & $1.200,00$ \\
\hline
\end{tabular}

$$
30.000=\frac{1.200}{(1+i)^{1}}+\frac{31.200}{(1+i)^{2}} \quad \text { T.I.E. }=4 \%
$$

Puesto que al cierre de ejercicio sólo se periodificarán los intereses explícitos no es necesario calcular el cuadro de amortización.

1-7-X: Adquisición de los valores: 


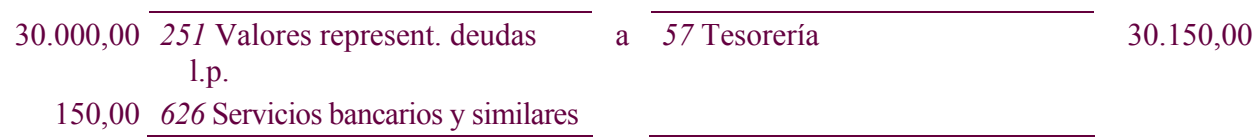

31-12-X: Periodificación intereses explícitos:

\begin{aligned} & 600,00 $\begin{array}{c}546 \text { Intereses c.p. de valores } \\ \text { representativos de deudas } \\ (1.200 / 2)\end{array} \\ &$\hline\end{aligned}

761 Ingresos de valores

representativos de deudas

600,00

Al cierre de ejercicio estos títulos tienen un valor de mercado superior al de coste $(12 €)$ por lo que, en principio, no existe evidencia de deterioro.

\section{b) Acciones REPSA:}

Se incluyen en la cartera de activos financieros mantenidos para negociar, luego la valoración se efectuará por su valor razonable con cambios en la cuenta de pérdidas y ganancias:

13-10-X: Adquisición de los valores:

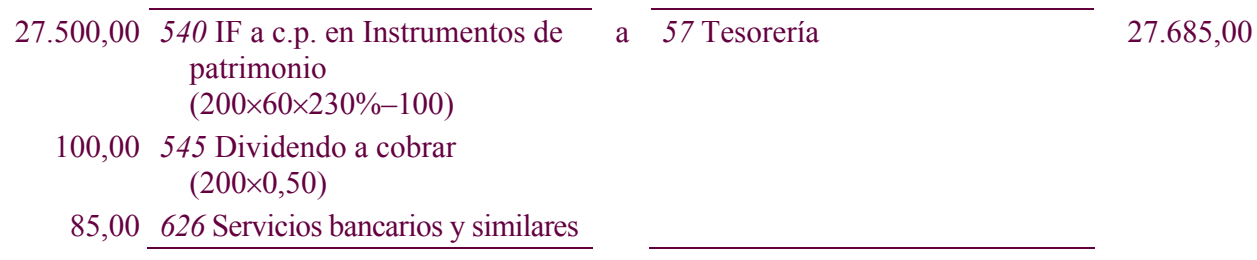

20-10-X: Cobro del dividendo:
$100,00 \overline{572 \text { Bancos c/c (se prescinde de }}$ a $\overline{545 \text { Dividendo a cobrar }} \quad 100,00$ las implicaciones fiscales)

31-12-X: Aplicación del nuevo valor razonable:

\begin{tabular}{|c|c|}
\hline Valor razonable actual: $200 \times 60 \times 205 \%$ : & $24.600,00$ \\
\hline Valor razonable anterior & $27.500,00$ \\
\hline Diferencia negativa & $(2.900,00)$ \\
\hline
\end{tabular}

2.900,00 6630 Pérdidas por valoración de inst. fin. por su valor razonable.

a 540 IF a 1.p. en Instrumentos de Cartera de negociación

\section{c) Acciones REPOSA:}

Como se trata de títulos no cotizados deberán ser clasificados en la categoría de Activos financieros a coste, calculando, en todo caso al cierre de ejercicio, las pertinentes correcciones valorativas si existe evidencia de deterioro.

22-11-X: Adquisición de los valores (se consideran como inversiones a corto plazo):

\begin{tabular}{cccc}
$35.500,00$ & $\begin{array}{l}540 \text { IF a c.p. en Instrumentos de } \\
\text { patrimonio }\end{array}$ & $35.500,00$ \\
\cline { 1 - 1 } & & 57 Tesorería &
\end{tabular}




\section{1-12-X: Deterioro del valor.}

En principio, y a falta de más información, existe evidencia de deterioro puesto que el coste inicial de una acción REPOSA es de 35,5€ (3.500/1.000) y su valor teórico al cierre de ejercicio se sitúa en $22 €(1.100 .000 / 50.000)$, por lo tanto es preciso efectuar la pertinente corrección valorativa para ajustar el valor inicial al valor teórico que se puede considerar como representativo del importe recuperable:

$\begin{array}{llll}13.500,00 & \begin{array}{l}698 \text { Pérdidas por deterioro de } \\ \text { participaciones a corto plazo } \\ (1.000 \times 13,5)\end{array} & \begin{array}{c}\text { 596 Deterioro de valor de } \\ \text { participaciones a corto plazo }\end{array} & 13.500,00 \\ & & \end{array}$

\section{ANÁLISIS DE LA PROBLEMÁTICA CONTABLE DE OPERACIONES CON VALORES DE RENTA FIJA}

\subsection{Consideraciones generales}

Como se indicó anteriormente, los valores de renta fija suelen tener la forma de activos financieros emitidos por empresas y entidades, tanto de carácter público como privado, que intervienen en los mercados financieros, o por el Tesoro Público y que normalmente se adquieren a través de los mercados de valores.

Constituyen pues, inversiones financieras cuyo vencimiento es conocido, así como el importe de su amortización y el rendimiento financiero que devengan en función del tiempo, por lo que se pueden clasificar también como activos monetarios. Cabe recordar asimismo, que estos títulos representan partes de un préstamo o empréstito emitido por otra entidad, razón por la cual se denominan en la terminología del Nuevo PGC como "valores representativos de deuda", incorporando, por tanto, los derechos propios de un acreedor, como son:

- Derecho al reembolso del principal de su deuda.

- Derecho a la percepción de los intereses derivados de la misma.

En consecuencia, cuando la entidad emisora de los títulos ha cumplido con sus obligaciones desaparece toda relación con la entidad inversora.

Formarán parte del activo corriente o circulante si su permanencia en la empresa es inferior al año (por ejemplo, si se adquieren para negociar) o del activo no corriente (inmovilizado financiero) en caso contrario. Concretamente, las cuentas previstas en la Cuarta y Quinta 
Parte del Borrador (Definiciones y Relaciones Contables y Cuadro de Cuentas, respectivamente) para reflejar toda la operatoria contable de estos títulos son las siguientes:

- Subgrupo 24. INVERSIONES FINANCIERAS A LARGO PLAZO EN PARTES VINCULADAS

241. Valores representativos de deudas a largo plazo de partes vinculadas

- Subgrupo 25. OTRAS INVERSIONES FINANCIERAS A LARGO PLAZO

251. Valores representativos de deuda a largo plazo

- Subgrupo 29. DETERIORO DE VALOR DE ACTIVOS NO CORRIENTES

294. Deterioro de valor de valores representativos de deuda a largo plazo de partes vinculadas

297. Deterioro de valor de valores representativos de deuda a largo plazo

- Subgrupo 53. INVERSIONES FINANCIERAS A CORTO PLAZO EN PARTES VINCULADAS

531. Valores representativos de deudas a corto plazo de partes vinculadas

533. Intereses a corto plazo de valores representativos de deuda de partes vinculadas

- Subgrupo 54. OTRAS INVERSIONES FINANCIERAS A CORTO PLAZO

541. Valores representativos de deuda a corto plazo

546. Intereses a corto plazo de valores representativos de deudas

- Subgrupo 59. DETERIORO DE VALOR DE INVERSIONES FINANCIERAS A CORTO PLAZO Y DE ACTIVOS NO CORRIENTES MANTENIDOS PARA LA VENTA

594. Deterioro de valor de de valores representativos de deuda a corto plazo de partes vinculadas

597. Deterioro de valor de de valores representativos de deuda a corto plazo

En general, los activos financieros monetarios se caracterizan porque devengan un interés explícito, que se calcula en función de una base o principal de la deuda perfectamente definida en el contrato de emisión. Por tanto, como siempre se puede conocer o estimar todos los flujos de efectivo que generan estos activos, su valoración se puede realizar a partir del valor actual de los cobros futuros a los que tiene derecho la 
empresa, en virtud de la posesión de estos activos. Así, para la actualización de los cobros futuros se toma una tasa de rendimiento financiero que es igual a la tasa interna de rentabilidad de la inversión. Es decir, se toma la tasa tal que el valor actual de los cobros futuros a la fecha de la inversión coincide con el desembolso o coste asumido para realizar la inversión (dicha tasa depende del tipo de interés explícito y de la cuantía de la diferencia que exista entre el coste del activo financiero y su valor de amortización). Esta forma de valoración, que hemos definido anteriormente como "coste amortizado", se aplicará en el caso de que las inversiones se adquieran con la intención de mantenerlas hasta el vencimiento, ya que en este caso el valor de mercado no les afecta, aunque sí pueden sufrir un deterioro como consecuencia del riesgo de crédito del deudor o del riesgo de cambio para los títulos contratados en moneda distinta del euro.

Como ya se ha indicado, estas inversiones se valorarán por su valor razonable cuando se adquieren para negociar o están disponibles para la venta; su problemática contable se analiza posteriormente con un ejemplo.

La rápida evolución experimentada por los mercados ha dado lugar al nacimiento de múltiples tipos de activos financieros, cada uno de los cuales tiene características particulares que lo diferencian de los demás. Así, cabe destacar los siguientes tipos de valores de renta fija:

- Obligaciones y bonos (emitida por empresas)

- Fondos públicos (deuda pública)

- Otros valores de renta fija (pagarés de empresas, letras bursátiles, etc.)

Por otro lado, en la mayor parte de los casos estas inversiones en valores de renta fija suelen cotizar en un mercado secundario organizado que se caracteriza, entre otras cosas, porque los precios son función directa de la relación entre los intereses del mercado a la fecha y los intereses explícitos que devenga el título que se valora. Por ejemplo, si un empréstito que vence dentro de tres años ofrece un interés del $5 \%$ anual sobre su valor nominal, y el interés del mercado, para inversiones de igual plazo y análogo riesgo, es el $4 \%$ anual, lo más probable es que el mencionado empréstito cotice en el mercado secundario por encima de su valor nominal, alcanzando un precio tal que la tasa interna de rentabilidad que se obtendría, si se paga este precio, estaría próxima al $4 \%$ anual.

Asimismo, el precio de mercado de los títulos incluye el importe de los intereses devengados hasta la fecha y no vencidos (cupón 
corrido), ya que estos intereses los percibirá el propietario de los títulos cuando llegue su vencimiento, es decir, si prescindimos de otros factores que pueden afectar a la valoración de los títulos (riesgo de mercado por insolvencia del deudor, o riesgo de cambio), la evolución que experimentan estas inversiones en el tiempo se puede representar por el siguiente gráfico en el que se puede observar cómo a medida que se acerque el momento del cobro de intereses, la cotización de los títulos se incrementará, para disminuir inmediatamente después de su reparto:

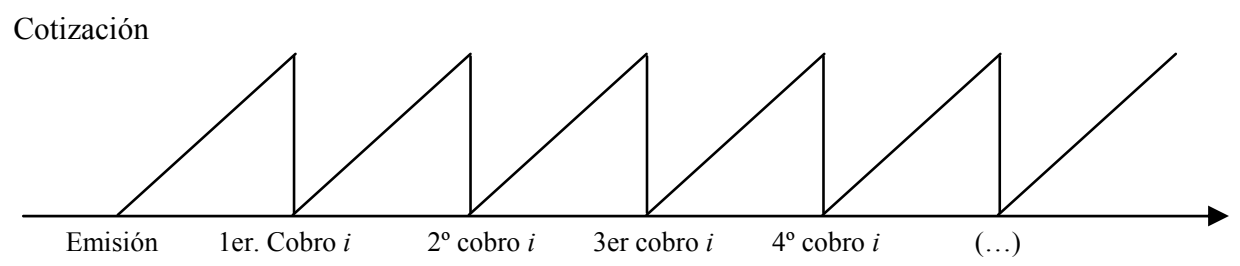

Teniendo en cuenta estas características básicas, a continuación se analizan dos problemáticas concretas que se pueden presentar con relación a estas inversiones en renta fija como son: la existencia de lo que se conoce como cupón corrido en el momento inicial de su adquisición y los denominados intereses implícitos o diferencia entre el precio inicial y el valor de reembolso.

corrido") ${ }^{5}$

\subsection{Intereses explícitos devengados y no vencidos ("cupón}

En algunos casos, los activos financieros se adquieren con el derecho a recibir una parte de los intereses ya devengados en un periodo anterior.

Esto es lo que ocurre cuando se compran obligaciones con cupón corrido, siendo necesario diferenciar, en el precio de adquisición, entre la parte que corresponde al derecho a percibir los intereses

$5 \quad$ Actualmente la mayor parte de las inversiones en valores de renta fija se suelen representar por medio de anotaciones en cuenta, razón por la cual ya no tiene sentido utilizar el término "cupón" como "instrumento" propiamente dicho; sin embargo, en la práctica se sigue utilizando este concepto como sinónimo del devengo de los intereses explícitos que genera la inversión. 
devengados en un período anterior y la parte que corresponde realmente al precio de adquisición del activo financiero.

Como ya se indicó al estudiar la composición de las tres principales carteras de valores que se pueden identificar en función del criterio de valoración aplicable en cada caso (coste amortizado o valor razonable), la normativa del nuevo PGC establece que en todas las carteras (mantenida hasta vencimiento, de negociación o disponible para la venta) la valoración inicial de los títulos se realizará por el precio de la transacción que equivaldrá al valor razonable de la contraprestación entregada más todos los gastos de transacción que les sean directamente imputables (con la excepción de la cartera de negociación en la que se imputarán directamente a pérdidas y ganancias), deduciendo, en su caso, el importe correspondiente a intereses explícitos devengados y no vencidos en el momento de su adquisición, los cuales se contabilizarán de forma independiente atendiendo a su vencimiento.

\section{Ejemplo n ${ }^{0}$ 9.-}

Supóngase un empréstito de obligaciones a 5 años emitido por la empresa "EMISA" el día 1-2-X, de $10 €$ de valor nominal, con un interés explícito del 4\% anual, pagadero por trimestres vencidos (valor emisión $=$ valor reembolso $=100 \%$ ). La empresa "COMPRASA" adquiere 9.000 títulos al 102\% el día 1-10-X, ascendiendo los gastos derivados de la comisión bancaria a $100 €$.

\section{Solución.-}

La evolución temporal del valor de lo títulos en función del vencimiento de los correspondientes cupones se puede representar mediante el siguiente gráfico:

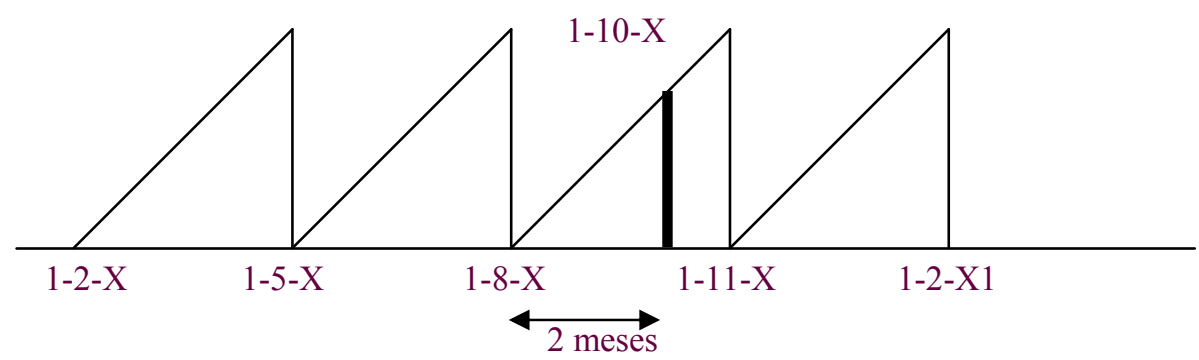

Importe total satisfecho: $9.000 \times 10 \times 102 \%+100$

$91.900,00$

Cupón corrido: $9.000 \times 10 \times 4 \% \times 2 / 12$

$(600,00)$ 
La contabilización de la operación en función de la cartera a la que se destine sería la siguiente:

a) Cartera de inversiones mantenidas hasta vencimiento

1-10-X:

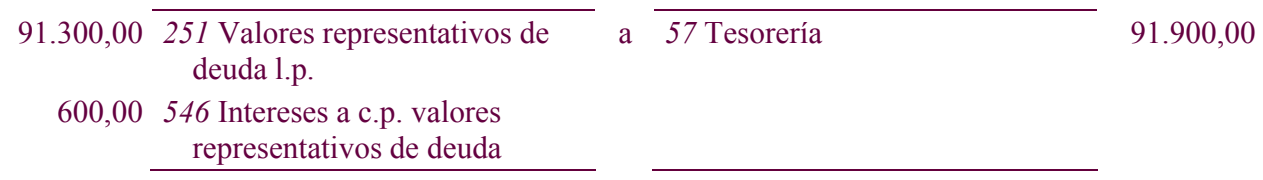

b) Cartera de activos financieros mantenidos para negociar

1-10-X:

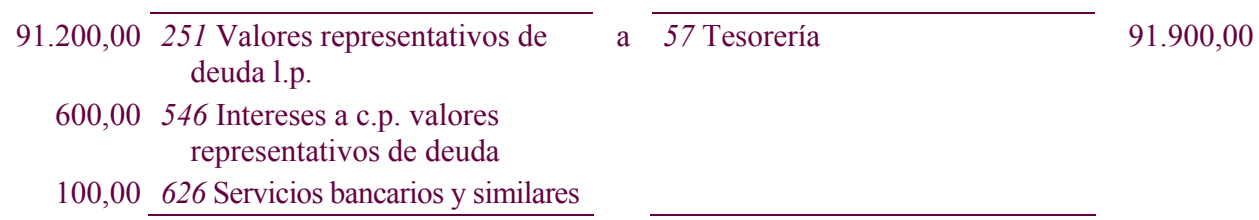

c) Cartera de activos financieros disponibles para la venta

1-10-X:

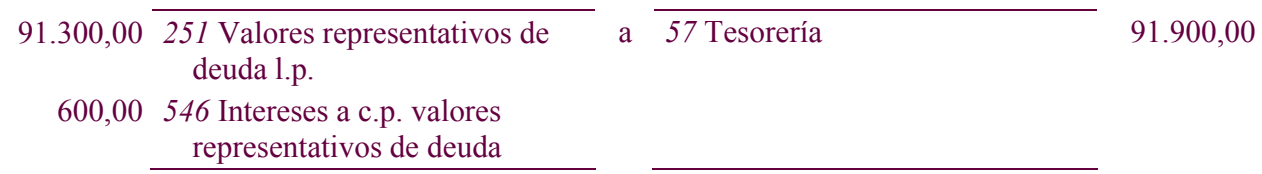

\subsection{Intereses implícitos}

Otro aspecto a tener en cuenta en la contabilización de los activos financieros representados por valores de renta fija es la posible existencia de diferencias entre el precio de adquisición de los mismos y el precio de amortización.

Dependiendo del signo que tengan estas diferencias, las mismas suponen un incremento o una disminución del rendimiento financiero real de la inversión. Éste pasará a ser superior o inferior, según corresponda al marcado por el tipo de interés que devenga la inversión, el cual se aplica sobre la base del valor nominal de los títulos representativos de la deuda.

Partiendo de la aplicación del principio del devengo, estos intereses deberán ser periodificados a lo largo de la vida del título, utilizando el tipo de interés efectivo de la inversión, es decir, teniendo en cuenta tanto los intereses explícitos como los implícitos, de forma que en 
cada período se obtenga un porcentaje de interés igual sobre el importe inicial de la inversión, obteniendo así el coste amortizado de la inversión ${ }^{6}$.

Por lo que respecta a los intereses implícitos positivos, éstos aparecen cuando el valor de reembolso supera al precio de adquisición, dando lugar a lo que se conoce como "prima de amortización" que puede ser de dos tipos:

a) Prima de emisión, cuando los títulos se emiten bajo la par y se reembolsan a la par (ejemplo: emisión al $90 \%$ y reembolso al $100 \%$ ).

b) Prima de reembolso, cuando los títulos se emiten a la par y se reembolsan sobre la par (ejemplo: emisión al 100\% y reembolso al $105 \%)$.

También pueden coexistir las dos primas a la vez, por ejemplo cuando la emisión se realiza bajo la par (ej: 90\%) y el reembolso sobre la par (ej: 105\%).

En algunos casos, la diferencia entre el coste de adquisición del activo financiero y su precio de amortización tiene signo negativo; es decir, el valor de lo recuperado al final de la inversión es menor que el importe invertido, surgiendo así los denominados intereses implícitos negativos. Esto ocurre, normalmente, cuando el tipo de interés explícito que devenga el activo financiero es mayor que el tipo medio que devengan otros activos financieros similares en el mercado. Por ello, sube su cotización, de forma que se llegan a pagar precios mayores que su valor de amortización, consiguiendo que la tasa interna de rentabilidad de la inversión se aproxime a los tipos de interés de mercado.

De todas formas, aunque no se ofrezca primas de amortización y el reembolso se efectúe por el nominal, es posible que siempre haya diferencias entre el valor de la inversión y el importe final recuperado, debido a la existencia de gastos de transacción cuando éstos se consideren como mayor valor de la inversión incrementando su coste. En cualquier caso, esta diferencia se distribuirá a lo largo de la vida de la inversión en función del tipo de interés efectivo como se ha indicado.

6 Cabe considerar que los intereses implícitos sólo se reflejarán contablemente cuando se trate de inversiones a vencimiento ya que en el resto de las carteras se supone que los títulos van a ser vendidos antes de vencimiento por lo que no darán lugar a diferencias entre el precio de coste y el de amortización. 


\section{Ejemplo n 10.- Intereses implícitos positivos}

\section{Supuesto $A$}

Una empresa adquiere el día 30 de junio del año X, 10 bonos de $1.000 €$ de valor nominal cada uno, emitidos por la empresa "XYZ" con fecha 1 de enero del mismo año que se negocian en un mercado activo, siendo su valor de cotización en dicha fecha de 9.000€. Los costes de transacción liquidados por la empresa ascienden a $100 €$ y decide clasificar dichos títulos como "Inversión mantenida hasta el vencimiento" ya que tiene la intención y capacidad financiera para mantener los bonos en esta categoría. Esta inversión ofrece una rentabilidad del 5\% de interés anual liquidable cada 31 de diciembre y su amortización tendrá lugar el 31-12-X1 por su valor nominal.

\section{Solución.-}

El gráfico que representa la evolución de la inversión a lo largo de los periodos considerados es el siguiente:

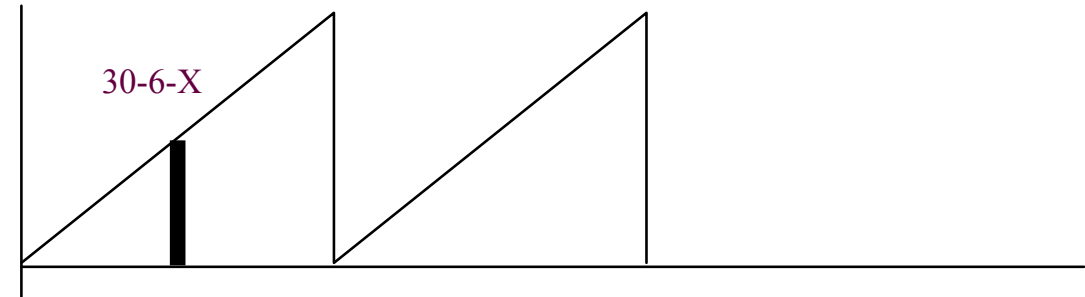
$1-1-X$
$31-12-\mathrm{X}$
$31-12-\mathrm{X} 1$

30-6-X:

Importe total satisfecho: $9.000+100$

Cupón corrido: $10 \times 1.000 \times 0,05 \times 6 / 12$

Precio transacción (valor razonable)

Importe cupón anual: $10 \times 1.000 \times 0,05$

Valor de reembolso: $10 \times 1.000$

$10.000,00$

Duración de la inversión (30-6-X - 31-12-X1): 18 meses

Cálculo del TIE:

$$
8.850+250=\frac{500}{(1+i)^{6 / 12}}+\frac{10.500}{(1+i)^{18 / 12}} \quad \quad \text { TIE }=13,9545 \%
$$

Cuadro de amortización:

\begin{tabular}{|c|c|c|c|c|}
\hline Fecha & Intereses & Cobros & Diferencia & $\begin{array}{c}\text { Coste } \\
\text { amortizado }\end{array}$ \\
\hline $30-6-X$ & - & - & - & 9.100 \\
\hline $31-12-X$ & $9.100(1+0,139545)^{6} / 12-9.100=614,20$ & 500 & 114,20 & $9.214,20$ \\
\hline $31-12-X 1$ & $1.285,80$ & 10.500 & $(9.214,20)$ & 0 \\
\hline
\end{tabular}


El registro contable de la operación en cada una de las fechas indicadas es la siguiente:

30-6-X: Adquisición de los valores:

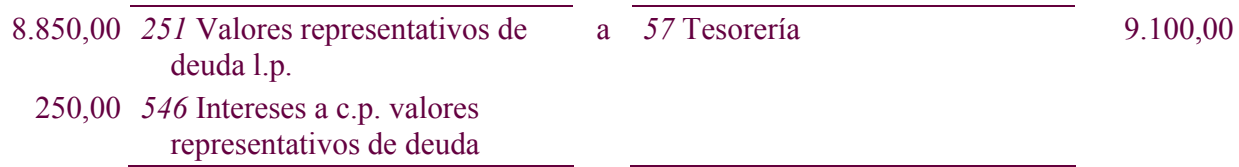

31-12-X: Periodificación intereses (explícitos e implícitos), cobro del cupón y reclasificación de la inversión:

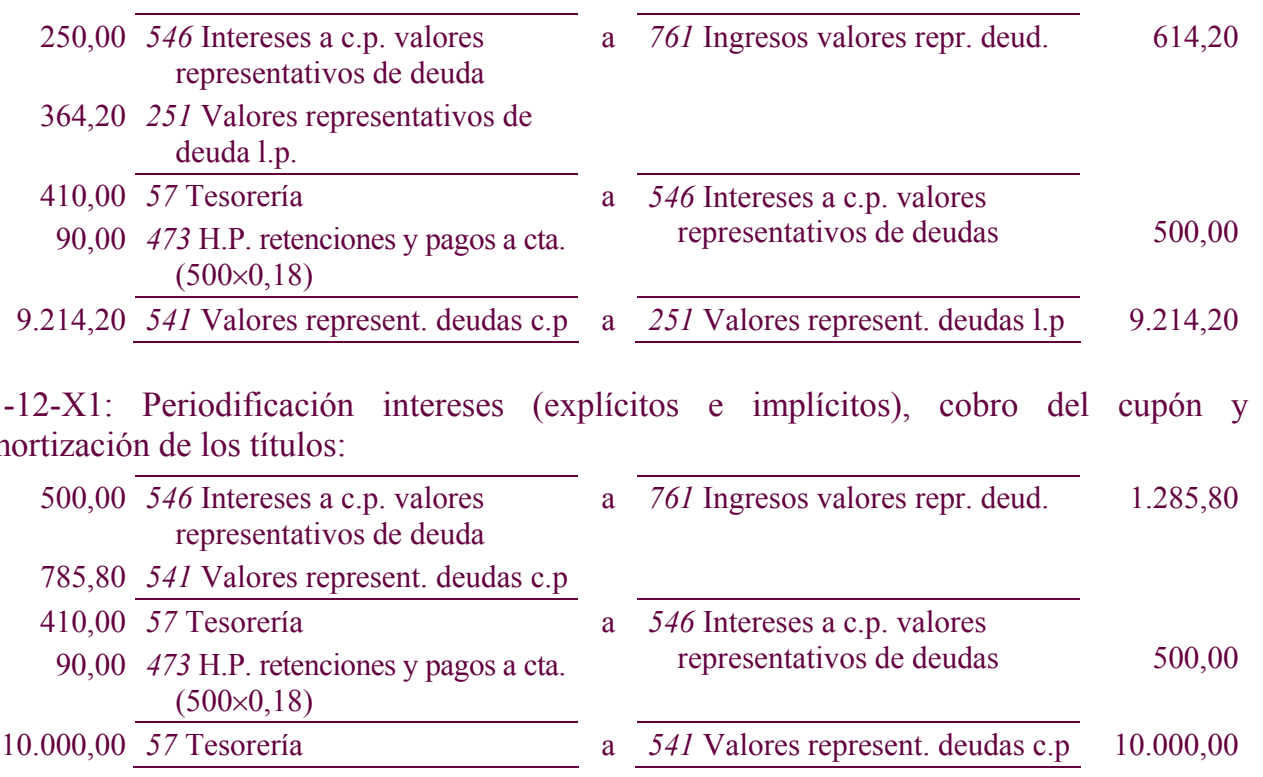

\section{Supuesto $B$}

El día 1-10-X se compran 9.000 títulos de $10 €$ de valor nominal, al 102\%, con un interés explícito del 4\% pagadero por semestres vencidos. Los títulos fueron emitidos el 1-2-Xy su amortización tendrá lugar el 1-2-X2 al 110\%. Gastos de comisión bancaria $100 €$.

\section{Solución.-}

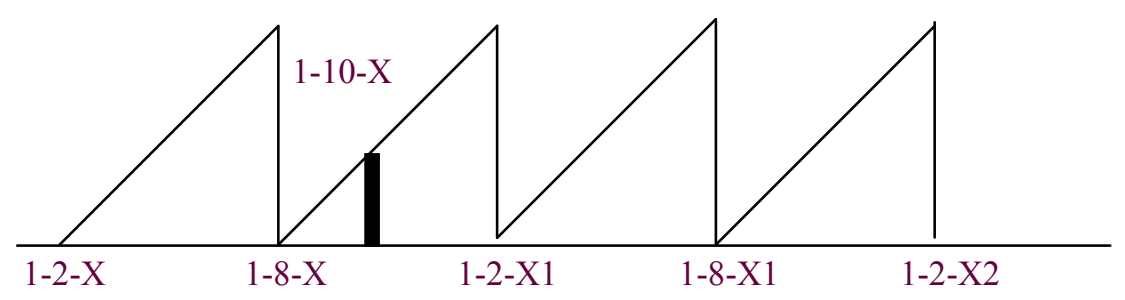

1-10-X: 


\begin{tabular}{|c|c|}
\hline Importe total satisfecho: $9.000 \times 10 \times 102 \%+100 \ldots \ldots$ & $91.900,00$ \\
\hline Cupón corrido: $9.000 \times 10 \times 4 \% \times 2 / 12$ & $(600,00)$ \\
\hline Precio transacción (valor razonable): $91.900-600$. & $91.300,00$ \\
\hline Importe cupón semestral: $9.000 \times 10 \times 4 \% \times 1 / 2 \ldots \ldots .$. & $1.800,00$ \\
\hline alor de reembolso $1-2-\mathrm{X} 1: 9.000 \times 10 \times 110 \%$ & $99.000,00$ \\
\hline
\end{tabular}

Cálculo del TIE:

$$
91.300+600=\frac{1.800}{(1+i)^{4 / 12}}+\frac{1.800}{(1+i)^{10 / 12}}+\frac{1.800+99.000}{(1+i)^{16 / 12}} \quad \quad \text { TIE }=10,254 \%
$$

Cuadro de amortización:

\begin{tabular}{|c|c|c|c|c|}
\hline Fecha & Intereses & Cobros & Diferencia & $\begin{array}{c}\text { Coste } \\
\text { amortizado }\end{array}$ \\
\hline $1-10-\mathrm{X}$ & - & - & - & 91.900 \\
\hline $31-12-\mathrm{X}$ & $91.900(1+0,10254)^{3} / 12-91.900=2.270,33$ & - & $2.270,33$ & $94.170,33$ \\
\hline $1-2-\mathrm{X} 1$ & 769,17 & 1.800 & $(1.030,83)$ & $93,139,51$ \\
\hline $1-8-\mathrm{X} 1$ & $4.658,75$ & 1.800 & $2.858,75$ & $95.998,26$ \\
\hline $31-12-\mathrm{X} 1$ & $3.985,09$ & - & $3.985,09$ & $99.983,35$ \\
\hline $1-2-\mathrm{X} 2$ & 816,65 & 100.800 & $(99.983,35)$ & 0 \\
\hline
\end{tabular}

El registro contable de la operación en cada una de las fechas indicadas es la siguiente:

1-10-X: Adquisición de los valores:

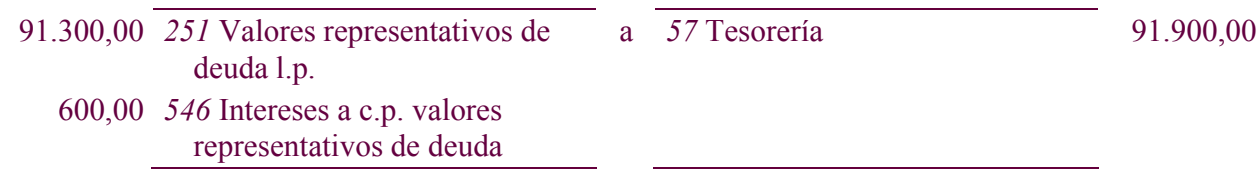

31-12-X: Periodificación intereses (explícitos e implícitos):
$900,00 \quad 546$ Intereses a c.p. valores
a 761 Ingresos valores repr. deud.
$(1.800 / 6 \times 3)$
$1.370,33251$ Valores representativos de deuda 1.p.
1-2-X1: Cobro del cupón:

\begin{tabular}{|c|c|c|c|}
\hline 300,00 & $\begin{array}{l}546 \text { Intereses a c.p. valores } \\
\text { representativos de deuda } \\
(1.800 / 6 \times 1)\end{array}$ & a & 761 Ingresos valores repr. deud. \\
\hline 469,17 & $\begin{array}{l}251 \text { Valores representativos de } \\
\text { deuda l.p. }\end{array}$ & & \\
\hline 476,00 & 57 Tesorería $(1800 \times 0,82)$ & a & 546 Intereses a c.p. valores \\
\hline 324,00 & 473 H.P. retenciones y pagos a cta. & & \\
\hline
\end{tabular}

1-8-X1: Cobro del cupón: 
abonaría por el cobro del cupón. Por otro lado, esta alternativa reflejaría de manera más adecuada la verdadera evolución del valor de los títulos, que aumenta cuando se devenga el interés explícito y disminuye cuando se cobra el cupón.

\section{Ejemplo $\mathbf{n}^{0}$ 11.- Intereses implícitos negativos}

\section{Supuesto $A$}

Una empresa adquiere el día 30 de junio del año $X, 10$ bonos de $1.000 €$ de valor nominal cada uno emitidos por la empresa "XYZ" con fecha 1 de enero del mismo año que se negocian en un mercado activo, siendo su valor de cotización en dicha fecha de $10.500 €$. Los costes de transacción liquidados por la empresa ascienden a $200 €$ y decide clasificar dichos títulos como "Inversión mantenida hasta el vencimiento" ya que tiene la intención y capacidad financiera para mantener los bonos en esta categoría. Esta inversión ofrece una rentabilidad del 5\% de interés anual liquidable cada 31 de diciembre y su amortización tendrá lugar el 31-12-X1 por su valor nominal.

\section{Solución.-}

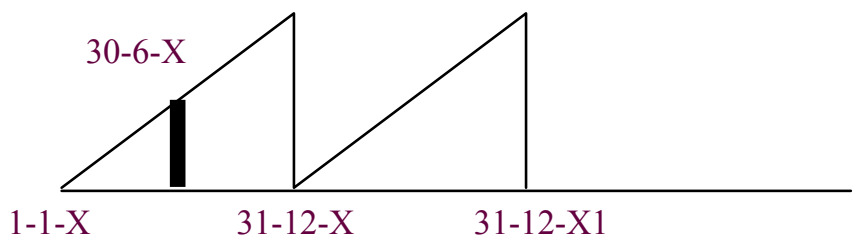

30-6-X:

\begin{tabular}{|c|c|}
\hline Importe total satisfecho: $10.500+200 \ldots \ldots \ldots .$. & $10.700,00$ \\
\hline Cupón corrido: $10 \times 1.000 \times 0,05 \times 1 / 2 \ldots$ & 250,00 \\
\hline Precio transacción (valor razonable) .............. & $10.450,00$ \\
\hline Importe cupón anual: $10 \times 1.000 \times 0,05 \ldots \ldots \ldots . .$. & 500,00 \\
\hline Valor de reembolso: $10 \times 1.000$ & $10.000,00$ \\
\hline
\end{tabular}

Cálculo del TIE:

$$
10.450+250=\frac{500}{(1+i)^{6 / 12}}+\frac{10.500}{(1+i)^{18 / 12}} \quad \text { TIE }=1,919781 \%
$$

Cuadro de amortización:

\begin{tabular}{|c|c|c|c|c|}
\hline Fecha & Intereses & Cobros & Diferencia & $\begin{array}{c}\text { Coste } \\
\text { amortizado }\end{array}$ \\
\hline $30-6-X$ & - & - & - & 10.700 \\
\hline $31-12-X$ & $10.700(1+0,01919781)^{6} / 12-10.700=102,22$ & 500 & $(397,78)$ & $10.302,22$ \\
\hline $31-12-X 1$ & 197,78 & 10.500 & $(10.302,22)$ & 0 \\
\hline
\end{tabular}


El registro contable de la operación en cada una de las fechas indicadas es la siguiente:

30-6-X: Adquisición de los valores:

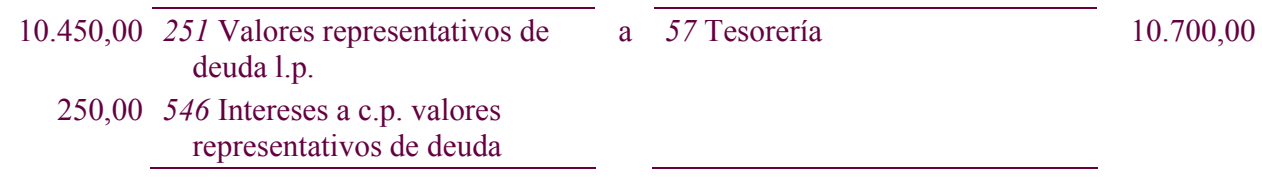

31-12-X: Periodificación intereses (explícitos e implícitos), cobro del cupón y reclasificación de la inversión:

\begin{tabular}{|c|c|c|c|}
\hline 250,00 & $\begin{array}{l}546 \text { Intereses a c.p. valores } \\
\text { representativos de deuda }\end{array}$ & & $\begin{array}{l}761 \text { Ingresos valores repr. deud. } \\
251 \text { Valores representativos de } \\
\text { deuda 1.p. }\end{array}$ \\
\hline 410,00 & 57 Tesore & $\mathrm{a}$ & 546 Intereses a c.p. valores \\
\hline 90,00 & 473 H.P. retenciones y pagos a cta. & & repre \\
\hline 302,22 & 541 Valores represent. deu. c.p. & $\mathrm{a}$ & 251 Valores represent. deudas 1.p \\
\hline
\end{tabular}

31-12-X1: Periodificación intereses (explícitos e implícitos), cobro del cupón y amortización de los títulos:

\begin{tabular}{|c|c|c|c|}
\hline & & & \\
\hline 500,00 & 546 Intereses a c.p. valores & $\mathrm{a}$ & 761 Ingresos valores repr. deud. \\
\hline & & $\mathrm{a}$ & $\begin{array}{l}541 \text { Valores representativos de } \\
\text { deuda c.p. }\end{array}$ \\
\hline 410,00 & 57 Tesorería & $\mathrm{a}$ & 546 Intereses a c.p. valores \\
\hline 90,00 & 473 H.P. retenciones y pagos a cta. & & \\
\hline $0.000,00$ & 570 Banco c/c & $\mathrm{a}$ & 541 Valores represent. deu. c.p. \\
\hline
\end{tabular}

\section{Supuesto B}

El día 1-10-X se compran 9.000 títulos de 10€ de valor nominal, al 102\%, con un interés explícito del 4\% pagadero por semestres vencidos. Los títulos fueron emitidos el 1-2-X y su amortización tendrá lugar el 1-2-X2 al 100\%. Gastos de comisión bancaria $100 €$.

\section{Solución.-}

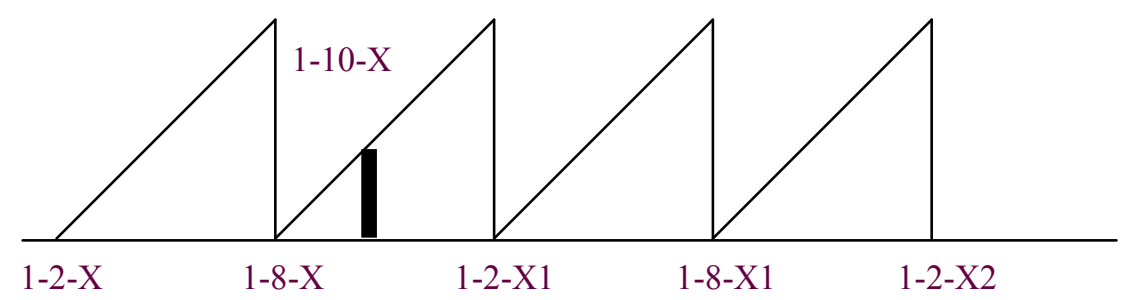

1-10-X:

Importe total satisfecho: $9.000 \times 10 \times 102 \%+100$

Precio transacción (valor razonable): 91.900-600 
Importe cupón semestral: $9.000 \times 10 \times 4 \% \times 1 / 2$

Cálculo del TIE:

$$
91.300+600=\frac{1.800}{(1+i)^{4 / 12}}+\frac{1.800}{(1+i)^{10 / 12}}+(1.800+90.000)^{16 / 12} \quad \text { TIE }=2,9063 \%
$$

Cuadro de amortización:

\begin{tabular}{|c|c|c|c|c|}
\hline Fecha & Intereses & Cobros & Diferencia & $\begin{array}{c}\text { Coste } \\
\text { amortizado }\end{array}$ \\
\hline $1-10-X$ & - & - & - & 91.900 \\
\hline $31-12-X$ & $91.900(1+0,)^{3} / 12-91.900=660,56$ & - & 660,56 & $92.560,56$ \\
\hline $1-2-X 1$ & 221,24 & 1.800 & $(1578,76)$ & $90.981,80$ \\
\hline $1-8-X 1$ & $1.312,62$ & 1.800 & $(487,38)$ & $90.494,42$ \\
\hline $31-12-X 1$ & $1.086,69$ & - & $1.086,69$ & $91.581,11$ \\
\hline $1-2-X 2$ & 218,89 & 91.800 & $(91.581,11)$ & 0 \\
\hline
\end{tabular}

El registro contable de la operación en cada una de las fechas indicadas es la siguiente:

1-10-X: Adquisición de los valores:

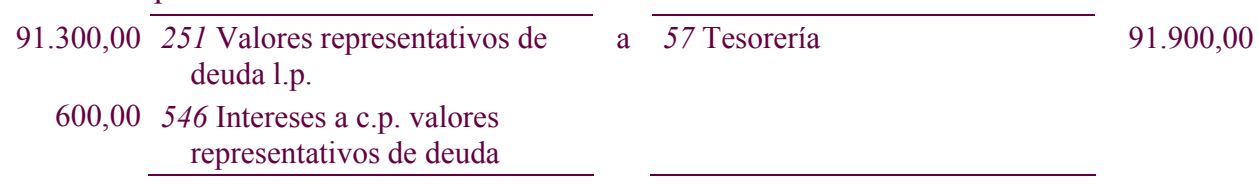

31-12-X: Periodificación intereses (explícitos e implícitos):

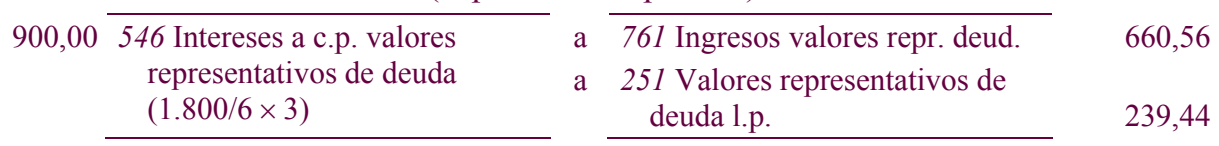

1-2-X1: Cobro del cupón:

\begin{tabular}{|c|c|}
\hline 300,00 & $\begin{array}{l}546 \text { Intereses a c.p. valores } \\
\text { representativos de deuda } \\
(1.800 / 6)\end{array}$ \\
\hline $1.476,00$ & 57 Tesorería $(1.800 \times 0,82)$ \\
\hline 324,00 & 473 H.P. retenciones y pagos a cta. \\
\hline
\end{tabular}

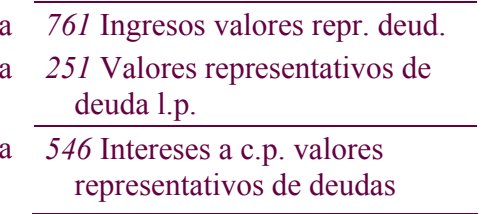

1-8-X1: Cobro del cupón:

$$
\begin{aligned}
1.800,00 & \begin{array}{r}
546 \text { Intereses a c.p. valores } \\
\text { representativos de deuda }
\end{array} \\
1.476,00 & \begin{array}{rl}
57 \text { Tesorería }(1.800 \times 0,82) \\
324,00 & 473 \text { H.P. retenciones y pagos a cta. }
\end{array} \\
\cline { 2 - 2 } &
\end{aligned}
$$$$
\text { a } 761 \text { Ingresos valores repr. deud. }
$$$$
\text { a } 251 \text { Valores representativos de }
$$$$
\text { deuda 1.p. }
$$

a 546 Intereses a c.p. valores

representativos de deudas

31-12-X1: Periodificación intereses (explícitos e implícitos) y reclasificación inversión: 


\begin{tabular}{|c|c|c|c|c|}
\hline \multirow[t]{2}{*}{$1.500,00$} & 546 Intereses a c.p. valores & $\mathrm{a}$ & 761 Ingresos valores repr. deud. & $1.086,69$ \\
\hline & $\begin{array}{l}\text { representativos de deuda } \\
(1.800 / 6 \times 5)\end{array}$ & a & $\begin{array}{l}251 \text { Valores representativos de } \\
\text { deuda 1.p. }\end{array}$ & 413,31 \\
\hline $0.081,11$ & 541 Valores represent. deudas c.p & a & $\begin{array}{l}251 \text { Valores representativos de } \\
\text { deuda l.p. }\end{array}$ & $90.081,11$ \\
\hline
\end{tabular}

1-2-X2: Cobro del cupón y amortización de la inversión:

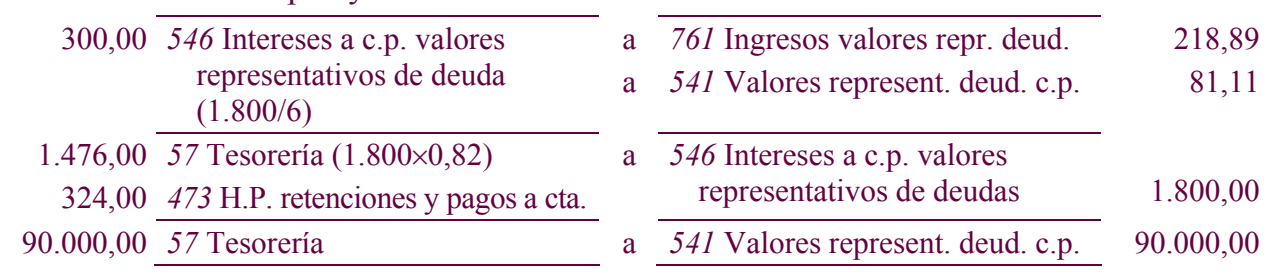

Finalmente, cabe comentar brevemente algunos casos particulares de valores de renta fija que presentan características especiales:

\section{Emisiones "cupón cero"}

Las obligaciones cupón cero son aquellas en las que los intereses se cobran de una sola vez al amortizarse los títulos, si bien en este caso, los intereses devengados se acumulan al capital para el cálculo de nuevos intereses, siguiendo una capitalización compuesta. No obstante, en este tipo de inversiones también se deberá seguir el mismo proceso anterior; es decir, se deben contabilizar los intereses a medida que se devenguen, de acuerdo con el tipo de interés efectivo, calculando el cuadro de amortización como en los ejemplos anteriores, con la diferencia de que, en este tipo de inversiones, no se produce ningún cobro hasta la fecha de amortización de los títulos.

\section{Ejemplo $n^{0}$ 12.-}

El 1-1-X se adquieren 10.000 obligaciones reembolsables el 31-12-X1, cupón cero, de 10€ nominales, al 100\% de emisión y reembolso, que devengan un 10\% de interés anual. Costes de transacción $150 €$.

\section{Solución.-}

Cálculo del TIE: 
Capital total percibido al final de la inversión:

$$
C f=100.000(1+0,1)^{2}=121.000 \quad 100.150=\frac{121.000}{(1+i)^{2}} \quad \text { TIE }=9,917593 \%
$$

Cuadro de amortización:

\begin{tabular}{|c|c|c|c|c|}
\hline Fecha & Intereses & Cobros & Diferencia & $\begin{array}{c}\text { Coste } \\
\text { amortizado }\end{array}$ \\
\hline $1-1-\mathrm{X}$ & - & - & - & 100.150 \\
\hline $31-12-\mathrm{X}$ & $9.932,47$ & - & $9.932,47$ & $110.082,47$ \\
\hline $31-12-\mathrm{X} 1$ & $10.917,53$ & 121.000 & $(110.82,47)$ & 0 \\
\hline
\end{tabular}

1-1-X: Adquisición de los títulos (no hay cupón corrido):

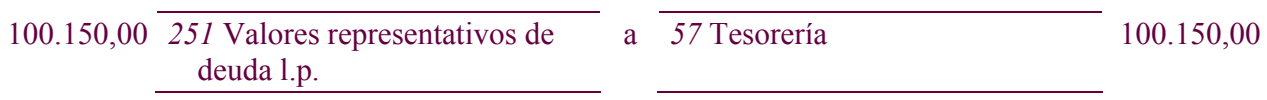

31-12-X: Periodificación intereses explícitos y reclasificación de la inversión:

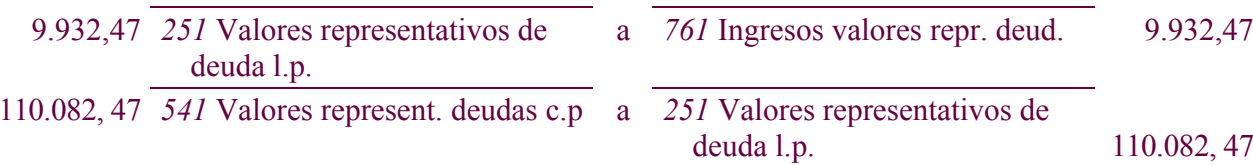

31-12-X1: Periodificación intereses explícitos y amortización de los títulos:

$\begin{array}{llll}10.917,53 \quad 541 \text { Valores represent. deudas c.p a } & \text { 761 Ingresos valores repr. deud. 10.917,53 }\end{array}$

$\begin{array}{llll}121.000,00 & 57 \text { Tesorería } & \text { a } \overline{541 \text { Valores represent. deudas c.p }} 121.000,00\end{array}$

\section{Títulos emitidos al descuento}

Se trata de una modalidad de emisión propia de los valores que no tienen cupones periódicos. Los títulos emitidos al descuento son aquellos en los que los intereses se descuentan en el momento de la emisión de los mismos, de forma que el inversor adquiere dichos títulos a un valor inferior al de reembolso. Suelen emitirse por debajo de su valor nominal y reembolsarse por dicho importe, siendo la diferencia entre el precio de adquisición y su nominal el descuento (intereses implícitos) que representa la rentabilidad absoluta que obtiene el inversor. Dentro de la deuda Pública, es la forma de emisión que se utiliza para las Letras del Tesoro. Su tratamiento contable es el mismo que se ha indicado para las primas de emisión, esto es, el importe de los intereses implícitos deberá ser contabilizado igualmente en el ejercicio en que se devengue de acuerdo con el tipo de interés efectivo. 
Ejemplo n ${ }^{0}$ 13.-

El 1 de octubre del año X, fecha de su emisión, se adquiere una letra del Tesoro de 10.000€ a un año, desembolsando $8.800 €$.

Solución.-

En este ejemplo, al no haber gastos de transacción y tener una duración de un año, el TIE coincide con el tipo de interés nominal $(13,636363 \%)$ los intereses por tanto son 1.200.

1-10-X. Adquisición de los valores:

\begin{tabular}{|c|c|c|c|}
\hline $8.800,00$ & $\begin{array}{l}541 \text { Valores representativos de } \\
\text { deuda c.p. }\end{array}$ & $\mathrm{a}$ & 57 Tesorería \\
\hline
\end{tabular}

31-12-X: Periodificación intereses implícitos:

285,78 $\overline{541 \text { Valores represent. deudas c.p }}$ a $\overline{761 \text { Ingresos valores repr. deud. }} \quad 285,78$ $\left[8.800 \times(1+0,1363)^{\wedge} 3 / 12\right)-$ $8.800]$

31-12-X1: Periodificación intereses implícitos y amortización de los títulos:

\begin{tabular}{|c|c|c|c|}
\hline 914,22 & 541 Valores represent. deudas c.p & a & 761 Ingresos valores repr. deud. \\
\hline $0.000,00$ & 57 Tesorería & $\mathrm{a}$ & 541 Valores represent. deudas c.p \\
\hline
\end{tabular}

\section{ANÁLISIS DE LA PROBLEMÁTICA CONTABLE DE OPERACIONES CON VALORES DE RENTA VARIABLE}

\subsection{Consideraciones generales}

Como ya se ha indicado en apartados anteriores, los valores de renta variable se caracterizan porque respecto a ellos la empresa inversora no conoce con exactitud el importe que va a recuperar y tampoco tienen una fecha preestablecida de vencimiento, por lo que se les clasifica también como activos no monetarios.

De esta forma, la principal diferencia entre los valores de renta fija y las participaciones en capital o instrumentos de patrimonio (valores de renta variable) radica en que la posesión de los primeros no da derechos a ejercer influencia alguna en las entidades emisoras, de tal modo que la empresa tenedora es simplemente un acreedor con los derechos correspondientes a los mismos. 
Por el contrario, los poseedores de valores de renta variable son socios o accionistas de la empresa, y tienen los derechos que se derivan de tal condición establecidos en la Ley de Sociedades Anónimas:

1. Derechos económicos (susceptibles de valoración económica o dineraria):

a) Derecho a participar en los beneficios de la sociedad.

b) Derecho preferente de suscripción en el caso de posteriores ampliaciones de capital.

c) Derecho a participar en el patrimonio final resultante en caso de liquidación de la empresa.

2. Derechos políticos o administrativos (no son susceptibles de valoración económica o monetaria):

d) Derecho a participar en la Junta General de Accionistas.

e) Derecho al voto (en el caso de acciones que tengan incorporado tal derecho).

f) Derecho a estar informado.

Al igual que los títulos de renta fija, los instrumentos de patrimonio se incluirán en el activo corriente o circulante si su permanencia en la empresa es inferior al año (por ejemplo si se adquieren para negociar) o en el activo no corriente (inmovilizado financiero) en caso contrario. Concretamente, las cuentas previstas en la Cuarta y Quinta Parte del nuevo PGC (Definiciones y Relaciones Contables y Cuadro de Cuentas, respectivamente) para reflejar toda la operatoria contable de estos títulos son las siguientes:

- Subgrupo 24. INVERSIONES FINANCIERAS A LARGO PLAZO EN PARTES VINCULADAS

240. Participaciones a largo plazo en partes vinculadas

249. Desembolsos pendientes sobre participaciones a largo plazo en partes vinculadas

- Subgrupo 25. OTRAS INVERSIONES FINANCIERAS A LARGO PLAZO

250. Inversiones financieras a largo plazo en instrumentos de patrimonio

259. Desembolsos pendientes sobre participaciones en el patrimonio neto a largo plazo

- Subgrupo 29. DETERIORO DE VALOR DE ACTIVOS NO CORRIENTES 
293. Deterioro de valor de participaciones a largo plazo en partes vinculadas

- Subgrupo 53. INVERSIONES FINANCIERAS A CORTO PLAZO EN PARTES VINCULADAS

530. Participaciones a corto plazo en partes vinculadas

539. Desembolsos pendientes sobre participaciones a corto plazo en partes vinculadas

- Subgrupo 54. OTRAS INVERSIONES FINANCIERAS TEMPORALES

540. Inversiones financieras temporales en instrumentos de patrimonio

549. Desembolsos pendientes sobre participaciones en el patrimonio a corto Plazo

- Subgrupo 59. DETERIORO DE VALOR DE INVERSIONES FINANCIERAS A CORTO PLAZO Y DE ACTIVOS NO CORRIENTES MANTENIDOS PARA LA VENTA

593. Deterioro de valor de participaciones a corto plazo en partes vinculadas

Por lo que respecta a los criterios para valorar este tipo de activos, dependerán de la finalidad u objetivo de la inversión que se deberá determinar desde el momento inicial de la adquisición, ya que estas inversiones solamente pueden formar parte de dos carteras (de negociación o disponibles para la venta) y no se pueden efectuar reclasificaciones entre ellas, salvo cuando proceda calificar los activos adquiridos como inversión en el patrimonio de empresas del grupo, multigrupo o asociadas.

Conviene aclarar que las participaciones en capital que se adquieren con fines de control o para ejercer una influencia notable (cartera de control) no son consideradas como unas inversiones financieras stricto sensu, sino que más bien se trata de inversiones reales que representan a los activos y pasivos de las empresas controladas o en las que se tiene dominio compartido o influencia significativa. Esta es la razón de que las Normas Internacionales de Contabilidad, al contrario de lo que hace el nuevo PGC, no las hayan considerado incluidas dentro de los activos financieros siendo reguladas mediante la normativa establecida a efectos de consolidación contable.

Por otro lado, la cartera de control es, tal vez, la que menos problemas de valoración plantea, ya que siempre se va a valorar 
por su precio de coste, sin que se vea afectada por el valor de mercado, dado que la intención de la empresa participante es mantenerla de forma indefinida, a fin de ejercer el dominio o influencia significativa, con independencia del valor que estos títulos puedan adquirir en el mercado. No obstante lo anterior, deberán practicarse las correcciones valorativas necesarias siempre que exista evidencia objetiva de que el valor en libros de la inversión no será recuperable.

Con relación a las carteras de activos financieros mantenidos para negociar y la de activos financieros disponibles para la venta recordemos que su valoración inicial siempre se efectuará por el precio de la transacción que equivaldrá al valor razonable de la contraprestación entregada. Los costes de transacción se incluirán en dicho valor inicial, salvo en el caso de la cartera de negociación, que se contabilizarán directamente como gastos de ejercicio.

Asimismo, formará parte de la valoración inicial el importe de los derechos preferentes de suscripción que, en su caso, se hubiesen adquirido.

Por el contrario, el importe de los dividendos acordados por el órgano competente en el momento de la adquisición, no se incluirá en la valoración inicial de las inversiones correspondientes. Dichos dividendos se registrarán de forma independiente, atendiendo a su vencimiento.

La valoración posterior de los títulos de ambas carteras se efectuará siempre a su valor razonable llevando las diferencias que se produzcan, positivas o negativas, entre dos valores razonables consecutivos a:

- Pérdidas y ganancias, si se trata de títulos mantenidos para negociar, y

- Patrimonio neto en el caso de activos disponibles para la venta. Cuando el activo cause baja del balance, o se deteriore, estas diferencias se imputarán a la cuenta de pérdidas y ganancias.

7.2. Análisis de la problemática contable de la venta o segregación de los derechos de suscripción

Como se indicó en el apartado anterior, uno de los derechos susceptibles de valoración económica que poseen los accionistas como propietarios de una parte del capital de la empresa participada, es 
el "derecho de suscripción preferente en la emisión de nuevas acciones o de obligaciones convertibles"; es decir, en las ampliaciones de capital, ante la entrada de nuevos accionistas, los antiguos tienen derecho a suscribir un número de acciones proporcional al que ya posean, de forma que, si lo desean, siempre pueden seguir manteniendo el mismo porcentaje de participación.

La razón de ser de este derecho encuentra su justificación en la necesidad de ofrecer al socio una adecuada protección frente al peligro que representan los aumentos de capital, dado que estas ampliaciones pueden ser necesarias para la empresa, pero pueden tener importantes efectos negativos, para los antiguos accionistas, si no se realizan de forma adecuada.

Concretamente, si la ampliación se realiza a la par, se produce una dilución o el llamado "aguamiento" del valor de la acción, ya que su valor teórico desciende, con la lógica repercusión en Bolsa. Dicha reducción tiene su origen en el hecho de que las reservas acumuladas por la sociedad, después de la ampliación tienen que repartirse entre un número mayor de acciones.

Evidentemente, para que las acciones antiguas no vieran afectado su valor teórico, los suscriptores de los títulos nuevos deberían aportar a la sociedad justamente el valor teórico de aquellas, lo que implicaría realizar la ampliación con prima. El problema en este caso vendría motivado por el mercado de capitales, que no siempre reacciona positivamente ante este tipo de ampliaciones.

Asimismo, queda claro que los nuevos accionistas que entrasen en la sociedad se incorporarían con todos los derechos que se reconocen a los socios, por lo que pasarían a participar en unos recursos constituidos por las reservas acumuladas hasta la fecha de la ampliación de capital, reservas que ellos no han contribuido a formar.

De esta forma, el derecho de suscripción es una forma de evitar estas consecuencias negativas o al menos de paliar sus efectos, ya que se pueden distinguir dos perfiles en el derecho de suscripción:

- Administrativo, según el cual el accionista puede seguir manteniendo una proporción de decisión semejante a la que tenía antes de la ampliación de capital.

- Económico, que influye en la proporción que el accionista tiene en las reservas de la sociedad. 
Es decir, si el accionista no suscribe una parte proporcional de los títulos emitidos se rompe el equilibrio existente antes de la ampliación, con dos efectos perniciosos:

- Económico, por la pérdida de valor patrimonial, al disminuir el valor de las acciones como consecuencia de tener que dividirse el patrimonio social entre un número mayor de acciones.

- Político, por pérdida de poder en la gestión de la sociedad.

No obstante, el poseedor de un derecho de suscripción (accionista antiguo) ante una ampliación de capital tendrá cuatro alternativas posibles:

$1^{\text {a }}$. Acudir a la ampliación y adquirir el mismo número de acciones que le corresponden según su proporción (mantiene su participación).

$2^{\mathrm{a}}$. No acudir a la ampliación y vender los derechos de suscripción a quien quiera comprar nuevas acciones (reduce su participación en la misma proporción que la relación entre el número de acciones nuevas y antiguas). De esta manera, el precio de venta del derecho vendría a compensar la pérdida del valor que la acción antigua experimenta como consecuencia de la ampliación.

$3^{a}$. Acudir a la ampliación y comprar menos acciones nuevas de las que proporcionalmente le corresponden, vendiendo el resto de derechos de suscripción (reduce su participación en un porcentaje inferior a la relación entre el número de acciones nuevas y antiguas).

$4^{a}$. Acudir a la ampliación y adquirir más acciones de las que proporcionalmente pude suscribir como máximo (incrementa su participación en la empresa).

Conviene destacar, no obstante, que existen determinadas modalidades de ampliación de capital en las que los antiguos accionistas, por las características de la contrapartida de las acciones emitidas, no poseen el anterior derecho, concretamente en los siguientes casos:

- Cuando la ampliación se realice para recibir una determinada aportación no dineraria, ya que en este caso las acciones serán suscritas por el propietario del bien entregado. 
- En el caso de una ampliación por absorción de otra empresa; los títulos serán suscritos por los accionistas de la sociedad absorbida.

- Cuando la ampliación se realice por compensación de créditos; en este caso será el prestamista el suscriptor de las nuevas acciones.

- Lo mismo ocurre en el caso de ampliación de capital por conversión de obligaciones en acciones, si bien la Ley de Sociedades Anónimas establece que los accionistas de la sociedad tendrán derecho preferente de suscripción de las obligaciones convertibles.

Desde el punto de vista contable, la suscripción de nuevas acciones no plantea ningún problema añadido, ya que la adquisición de los nuevos títulos se contabilizará, como se ha indicado en los apartados anteriores, de acuerdo con la clasificación de la inversión (cartera de negociación o disponible para la venta) teniendo en cuenta que en la alternativa 4 (compra de más acciones de las que proporcionalmente corresponden), el importe de los derechos que sean necesario adquirir formará parte de su valoración.

Sin embargo, el problema se plantea en las alternativas $2^{\mathrm{a}} \mathrm{y}$ $3^{a}$, ya que en ambos casos se procede a la venta de derechos de suscripción. El tratamiento contable en estos casos depende de la consideración que quiera darse al producto que se obtenga por la enajenación de los derechos.

Desde un punto de vista teórico, existen tres posibilidades en cuanto al tratamiento del precio de venta de los derechos:

a) Considerar que con la venta de los derechos se está procediendo a la enajenación de una parte de las acciones de las que se derivan los correspondientes derechos, lo que implicaría disminuir el valor de las acciones en el precio de venta de los derechos.

b) Considerar el precio de venta de los derechos como un rendimiento más, al igual que los dividendos, lo que significaría contabilizar el producto de la venta como un ingreso de naturaleza financiera.

c) Una última posibilidad, intermedia entre las dos anteriores, será considerar que con la enajenación de los derechos se produce la venta de una parte de la acción y la diferencia entre el precio de venta del derecho y el importe por el que se debe disminuir el valor de las acciones determinará el beneficio o pérdida obtenida en la operación. 
Parece ser que, en la práctica profesional, esta última alternativa es la comúnmente admitida, ya que en realidad la venta de los derechos supone una disminución del valor de las acciones y al mismo tiempo esta operación puede generar un resultado para la empresa, positivo o negativo, dependiendo del precio obtenido por la venta de los derechos. Por otro lado, cuando se trate de títulos admitidos a cotización oficial, en el momento de anunciarse la ampliación de capital lo que antes era un activo único (la acción) ahora se desdobla en dos: por un lado la acción ex-derecho y por otra parte, el propio derecho de suscripción cuya cotización se separa del de la acción con el fin de que se pueda negociar de forma independiente para aquellos que quieran comprar o vender derechos.

Es por ello, que el nuevo PGC, al igual que el derogado de 1990 , establece en su norma de registro y valoración $n^{0} 9^{7}$ que, "en el caso de venta de derechos preferentes de suscripción y similares o segregación de los mismos para ejercitarlos, el importe de los derechos disminuirá el valor contable de los respectivos activos".

El problema se plantea, entonces, a la hora de determinar el importe por el que se disminuirá el valor de las acciones, ya que según la nueva normativa las acciones figuran en el balance, generalmente, por su valor razonable (con cambios en pérdidas y ganancias o en patrimonio neto, según la cartera a la que se hayan asignado), y excepcionalmente por su precio de coste (acciones no cotizadas para las que no se pueda determinar un valor razonable fiable), debiéndose calcular qué parte del valor de las acciones corresponde al valor de de los derechos. En este sentido, el nuevo Plan establece que "dicho importe corresponderá al valor razonable o al coste de los derechos, de forma consistente con la valoración de los activos financieros asociados, y se determinará aplicando alguna fórmula valorativa de general aceptación".

Existen distintos procedimientos para determinar el valor del derecho de suscripción basados en distintos conceptos, como son el valor teórico de la acción antes de la ampliación, la cotización de las acciones antes de la ampliación, precio de coste y valor teórico del derecho y, en general, en relación con cualquier método de valoración de empresas.

El tratamiento previsto para la venta o segregación de los derechos preferentes de suscripción se recoge en el apartado 2.6 de la citada norma, que se refiere a la cartera de activos financieros disponibles para la venta. Se entiende que si los títulos cuyos derechos se enajenan forman parte de la cartera de negociación se seguirá un tratamiento similar. 
De entre todas las fórmulas propuestas, interesa destacar dos, ya que en la práctica son las más utilizadas:

\section{Valor teórico del derecho $=N(C-E) /(N+A)$}

Siendo $N$ el número de acciones nuevas, $C$ la cotización antes de la ampliación, $E$ el valor de emisión de las nuevas acciones y $A$ el número de acciones antiguas.

El empleo de esta fórmula tiene la ventaja de permitir conocer si el mercado secundario recoge, o no, adecuadamente el valor de dilución, pero plantea el inconveniente de que no considera el precio de adquisición de la acción antigua, por lo que se vulnera el principio del mismo nombre, según el cual si el derecho de suscripción forma parte del valor de la acción antigua, debe ser valorado proporcionalmente al coste de ésta. De esta forma, según este criterio dos accionistas que adquirieron sus títulos a distinto coste, en el caso de venta de sus derechos de suscripción reflejarían el mismo resultado.

\section{Fórmula de Kester}

Con la fórmula de Kester se consigue verificar el principio del precio de adquisición, dado que, si se considera el derecho de suscripción como parte del coste de una acción, la proporción que existe entre sus cotizaciones puede considerarse equivalente a la proporción que existirá entre sus precios de coste respectivos. Se puede establecer, por tanto, la siguiente proporción:

$$
\frac{\text { Coste derecho }}{\text { Cotización derecho }}=\frac{\text { Coste acción }}{\text { Cotización acción }}
$$

Como en la anterior expresión se conocen todos los valores excepto el correspondiente al coste del derecho, despejando dicha incógnita quedaría:

Coste del derecho $=\frac{\text { Cotización del derecho }}{\text { Cotización de la acción (incluyendo el derecho) }} \times$ Coste de la acción

Ahora bien, en la normativa que propone el nuevo Plan, según hemos indicado, solamente las acciones que se adquieren de una 
empresa del grupo o asociada (cartera de control) o títulos para los que no se puede determinar con fiabilidad su valor razonable (caso de acciones no cotizadas) se contabilizan al coste, por lo que en este caso la enajenación de los derechos de suscripción se puede seguir contabilizando de forma similar a la recogida en el Plan anterior, esto es, se abonarán las cuentas representativas de las acciones por el precio de coste de los derechos (calculado por la fórmula de Kester) llevando la diferencia entre dicho precio y el de venta de los derechos a "pérdidas o beneficios en participaciones". Asimismo, procederá reducir el importe de las correcciones valorativas contabilizadas en su caso.

Por otro lado, si las acciones que se han adquirido se han clasificado como mantenidas para negociar o disponibles para la venta, y para estas últimas el valor razonable se puede determinar de forma fiable, la enajenación de los derechos de suscripción se contabilizará abonando las cuentas representativas de los títulos por el valor en libros que corresponda a la parte del activo que se enajena, llevando la diferencia entre dicho importe y la contraprestación recibida como resultado del ejercicio en que ésta se produce. Cabe considerar además, que tratándose de títulos disponibles para la venta, la parte proporcional correspondiente a los importes acumulados reconocidos directamente en el patrimonio neto (como ganancias o pérdidas no realizadas) como consecuencia de los cambios en el valor razonable de los títulos, se llevará directamente a resultados, con el fin de determinar la ganancia o pérdida surgida en la operación.

El problema surge al determinar la parte del valor en libros que corresponda a los derechos. A este respecto, hay que recordar que dicho valor en libros se ha obtenido a partir del último valor razonable aplicado, que normalmente será su valor de mercado, el cual incorporará también el valor del derecho. Teniendo en cuenta que, como se ha explicado anteriormente, cuando se anuncia una ampliación de capital el valor del derecho y de la acción a efectos de cotización se separan, es posible aplicar el mismo razonamiento que en la fórmula de Kester anteriormente expuesta, de forma que el valor en libros del derecho se puede obtener a partir de la siguiente expresión:

Valor en libros derecho $=\frac{\text { Cotización del derecho }}{\text { Cotización acción (incluyendo cotiz. Derecho) }} \times$ Valor en libros de la acción 
Ejemplo $n^{0}$ 14.-

La sociedad anónima "ALFA" posee 3.500 acciones de la sociedad anónima "BETA" adquiridas en mayo del año $X$, a una cotización del 110\%, siendo su valor nominal de $10 €$ y los gastos de la comisión bancaria de 200€. Dichos títulos se clasifican como activos financieros mantenidos para negociar. El 31-12-X la cotización de las acciones BETA era del $108 \%$.

En el año X1, la sociedad "BETA" amplía capital en las siguientes condiciones: Proporción $2 \times 5$. Emisión a la par. Cotización de la acción antes de la ampliación: 112\%. Cotización del derecho de suscripción: 0,80€/derecho.

La sociedad "ALFA" decide:

1) Suscribir todas las acciones que correspondan

2) Vender todos los derechos a su valor de cotización

3) Suscribir sólo 1.000 acciones y vender los derechos no utilizados.

4) Suscribir 1.500 acciones, y comprar los derechos que sean necesarios.

\section{Solución.-}

Es preciso recordar que en esta cartera los costes de transacción no forman parte de la valoración inicial, por lo que se contabilizan directamente en pérdidas y ganancias el día de la adquisición mediante el siguiente asiento contable:

Mayo año X:

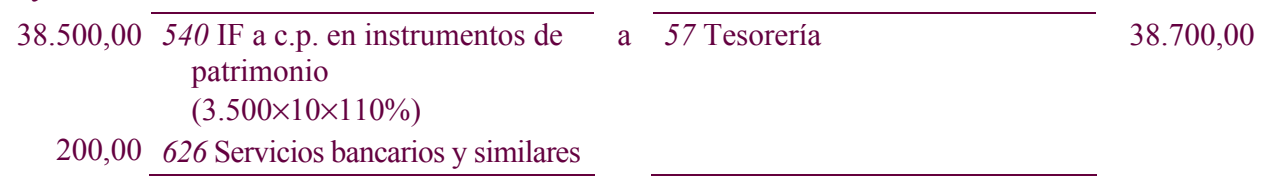

31-12-X:

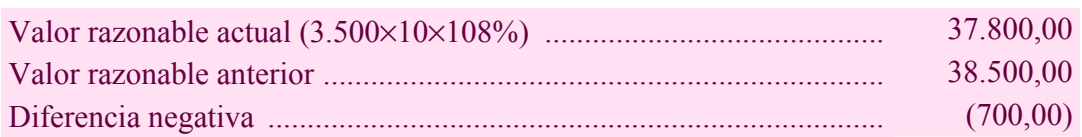

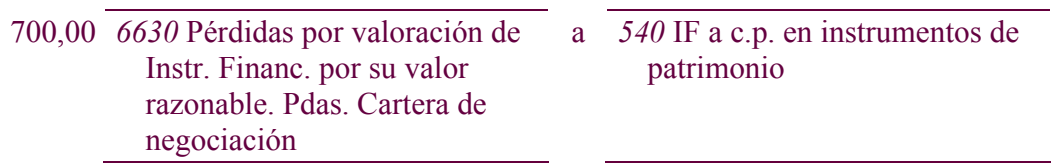

La situación contable de ALFA en relación con su cartera de activos financieros mantenidos para negociar en el ejercicio X1 en el que tiene lugar la ampliación de capital por parte de BETA, S.A. es la siguiente:

\section{Año X1:}

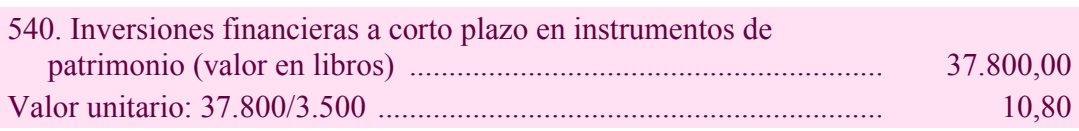


La contabilización de las operaciones realizadas en cada una de las alternativas propuestas es la siguiente:

\section{1) Suscribir todas las acciones:}

Teniendo en cuenta que, dada la proporción en que se realiza la ampliación, es necesario disponer de 5 acciones viejas para poder suscribir 2 acciones nuevas, con el total de los derechos que se poseen (3.500) se pueden suscribir como máximo $(3.500 \times 2 / 5) 1.400$ acciones nuevas. Por tanto, la suscripción de los nuevos títulos implica la siguiente anotación contable:

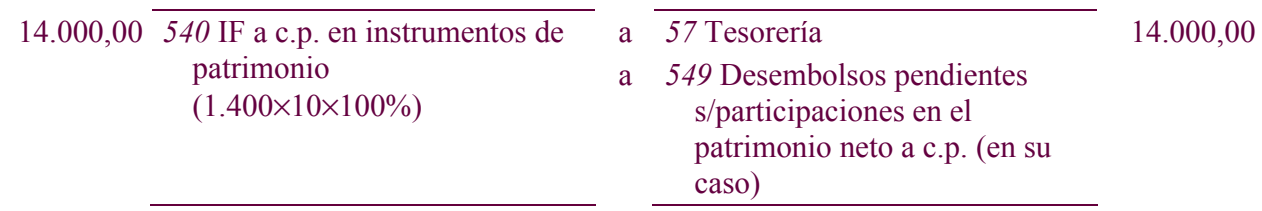

2) Vender todos los derechos a su valor de cotización:

$\mathrm{N}^{\mathrm{o}}$ derechos: 3.500 derechos ( $=\mathrm{n}^{\mathrm{o}}$ acciones antiguas)

1. Precio de venta $=0,80 € /$ derecho

Precio de venta total $=3.500 \times 0,80=2.800 €$

2. Valor en libros de derecho $=\frac{0,80}{10 \times 112 \%} \times 10,08 \cong 0,72$

Valor en libros derechos total $=0,72 \times 3.500=2.520$

RESULTADO $=$ Beneficio $=2.800-2.520=280 €$

$2.800,00 \quad 57$ Tesorería

$(3.500 \times 0,80)$ a 540 IF a c.p. en instrumentos de
patrimonio

766 Beneficios en participaciones y valores representativos de deudas
$2.520,00$

280,00

\section{Suscribir sólo 1.000 acciones y vender los derechos no utilizados}

Para suscribir 1.000 títulos nuevos es necesario disponer de 2.500 derechos $(1.000 \times 5 / 2)$. Como se poseen en total 3.500 derechos, se venden los derechos no utilizados:

$$
3.500-2.500=1.000 \text { derechos }
$$

a) Suscribe las acciones nuevas:

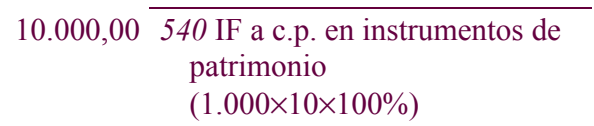

57 Tesorería
549 Desembolsos pendientes
s/participaciones en el
patrimonio neto a c.p. (en su
caso)

$10.000,00$ 


$$
\begin{array}{rl}
800,00 & 57 \text { Tesorería } \\
& (1.000 \times 0,80)
\end{array}
$$

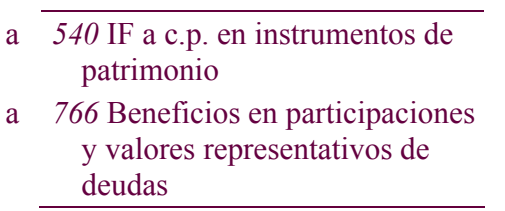

\section{Suscribir 1.500 acciones, comprando los derechos que sean necesarios}

En esta última alternativa, la sociedad necesita disponer un total de 3.750 derechos $(1.500 \times$ $5 / 2$ ). Como sólo tiene 3.500, necesita adquirir en el mercado 250 derechos más.

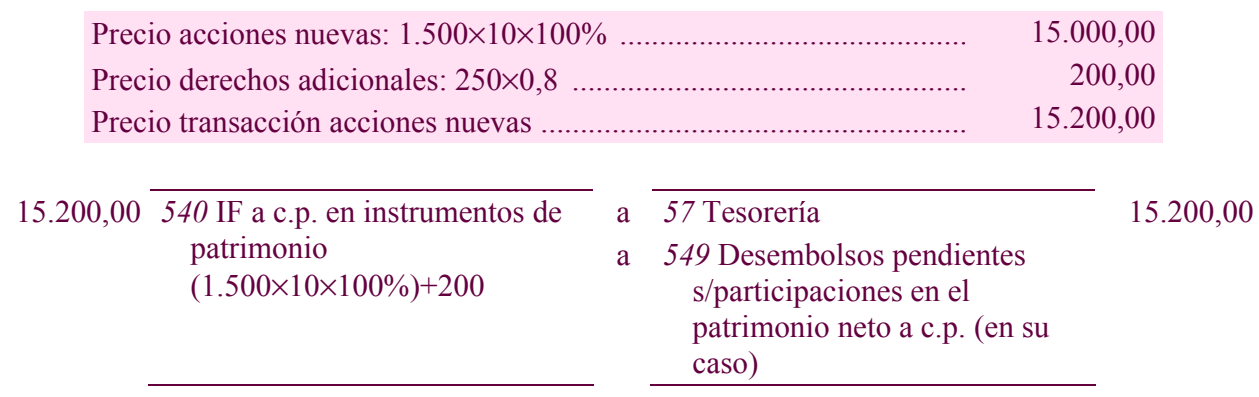

\section{Ejemplo n ${ }^{0}$ 15.-}

Partiendo de los mismos datos del Ejemplo 13, con la diferencia de que en este ejemplo los títulos se clasifican como activos financieros disponibles para la venta con la intención de enajenarlos en el año X2.

\section{Solución.-}

Como se recordará, cuando se trata de la cartera de activos financieros disponibles para la venta, los gastos de transacción forman parte de la valoración inicial de los títulos, por lo que la anotación contable que procede realizar en mayo del año X (fecha de adquisición) es la siguiente:

Mayo año X:

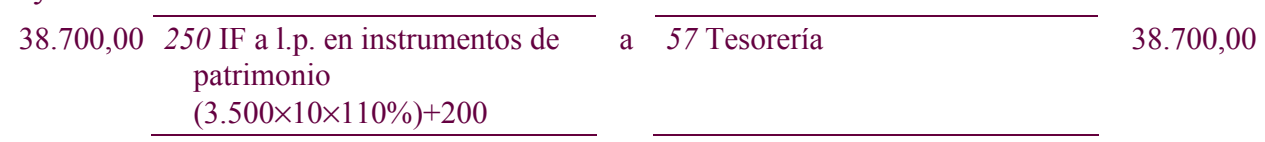

\begin{tabular}{|c|c|}
\hline Valor razonable actual $(3.500 \times 10 \times 108 \%) \ldots$ & $37.800,00$ \\
\hline 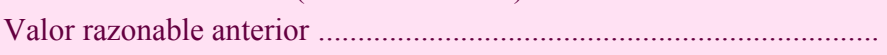 & $38.700,00$ \\
\hline diferencia negativa & $(900,00)$ \\
\hline
\end{tabular}

\section{1-12-X:}




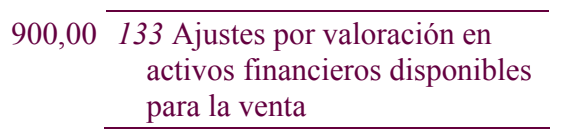

800 Pérdidas en activos financieros disponibles para la venta

900,00

La situación contable de ALFA en relación con su cartera de activos financieros disponibles para la venta en el ejercicio X1 en el que tiene lugar la ampliación de capital por parte de BETA, S.A. es la siguiente:

\section{Año X1:}

\begin{tabular}{|c|c|}
\hline $\begin{array}{l}\text { 250. Inversiones financieras a largo plazo en instrumentos de } \\
\text { patrimonio (valor en libros) }\end{array}$ & $37.800,00$ \\
\hline $\begin{array}{l}\text { Cuenta de patrimonio Neto: (133) Ajustes por valoración en activos } \\
\text { financieros disponibles para la venta (saldo deudor) }\end{array}$ & $(900,00)$ \\
\hline Valor unitario: $37.800 / 3.500$ & 10,80 \\
\hline
\end{tabular}

La contabilización de las operaciones realizadas en cada una de las alternativas propuestas es la siguiente:

\section{Suscribir todas las acciones:}

\begin{tabular}{|c|c|c|c|c|c|}
\hline 2 & ---- & 5 & & & \\
\hline $\mathrm{x}$ & ---- & 3.500 & & $\mathrm{x}=1.400$ accio & nuevas \\
\hline $14.000,00$ & 250 IF a 1 & en instrumentos de & $\mathrm{a}$ & 57 Tesorería & $14.000,00$ \\
\hline & $\begin{array}{l}\text { patrimo } \\
(1.400 \times\end{array}$ & $110 \%)$ & $\mathrm{a}$ & $\begin{array}{l}549 \text { Desembolsos pendientes } \\
\text { s/participaciones en el } \\
\text { patrimonio neto a c.p. (en su } \\
\text { caso) }\end{array}$ & \\
\hline
\end{tabular}

\section{Vender todos los derechos a su valor de cotización}

$\mathrm{N}^{\mathrm{o}}$ derechos: 3.500 derechos ( $=\mathrm{n}^{\circ}$ acciones antiguas)

1. Precio de venta $=0,80 € /$ derecho

Precio de venta total $=3.500 \times 0,80=2.800 €$

2. Valor en libros de derecho $=\frac{0,80}{10 \times 112 \%} \times 10,08 \cong 0,72$

Valor en libros derechos total $=0,72 \times 3.500=2.520$

Ajustes por valoración a imputar a resultados: $900 / 37.800 \times 2.520=60 €$

RESULTADO $=$ Beneficio $=2.800-2.520-60=220 €$

\begin{tabular}{|c|c|}
\hline $2.800,00$ & $\begin{array}{l}57 \text { Tesorería } \\
(3.500 \times 0,80)\end{array}$ \\
\hline 60,00 & $\begin{array}{l}6632 \text { Pérdidas por valoración de } \\
\text { instr. financieros por su valor } \\
\text { razonable Pérdidas de } \\
\text { disponibles para la venta }\end{array}$ \\
\hline
\end{tabular}
250 IF a l.p. en instrumentos de Patrimonio

a 766 Beneficios en participaciones y valores representativos de deudas

902 Transferencias de pérdidas de activos financieros disponibles para la venta 
Al cierre del ejercicio X1:

$\begin{array}{rl}60,00 & 902 \text { Transferencias de pérdidas } \\ \text { de activos financieros } \\ \text { disponibles para la venta }\end{array}$
133 Ajustes por valoración en activos financieros disponibles para la venta

60,00

\section{Suscribir sólo 1.000 acciones y vender los derechos que le sobren}

$$
\begin{aligned}
& 2 \quad---\quad 5 \\
& 1.000 \text {--- } \quad \text { X } \quad \text { X }=2.500 \text { derechos } \\
& \text { Sobran }=3.500-2.500=1.000 \text { derechos }
\end{aligned}
$$

a) Suscribe las acciones nuevas:

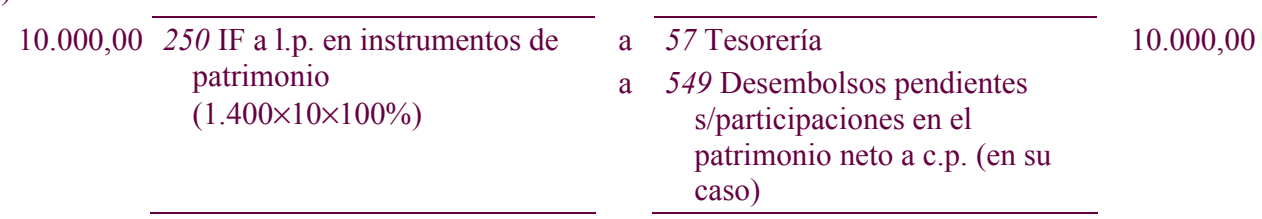

b) Vende el resto de derechos:

Precio de venta: $1.000 \times 0,8$

Valor en libros derechos vendidos: $0,72 \times 1.000$.......................................... $\quad 720,00$

Ajustes por valoración a imputar a resultados: $900 / 37.800 \times 720 \ldots \ldots \ldots \ldots \ldots \ldots \ldots \ldots \ldots$

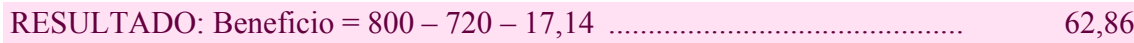

800,0057 Tesorería

$(1.000 \times 0,80)$

17,14 6632 Pérdidas por valoración de instr. Financieros por su valor razonable Pérdidas de disponibles para la venta
250 IF a 1.p. en instrumentos de Patrimonio

720,00

a 766 Beneficios en participaciones y valores representativos de deudas

80,00

a 902 Transferencias de pérdidas de activos financieros disponibles para la venta

Al cierre del ejercicio X1:

17,14902 Transferencias de pérdidas de activos financieros disponibles para la venta

a

133 Ajustes por valoración en
activos financieros disponibles
para la venta

\section{Suscribir 1.500 acciones, comprando los derechos que necesite}

$$
\begin{array}{lll}
2 & --- & 5 \\
1.500 & --- & \mathrm{x}
\end{array}
$$$$
\mathrm{x}=3.750 \text { derechos }
$$

Necesita $=3.750-3.500=250$ derechos

Precio acciones nuevas: $1.500 \times 10 \times 100 \%$

Precio derechos adicionales: $250 \times 0,8$

Precio transacción acciones nuevas 


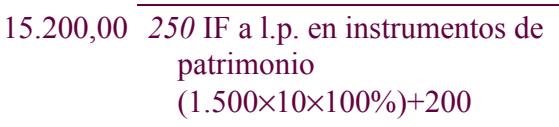

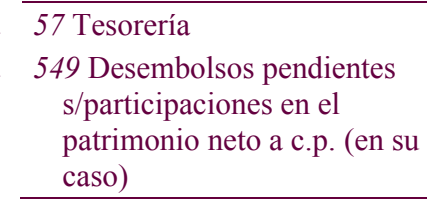

$15.200,00$

\section{BIBLIOGRAFÍA}

CañIBano Clavo, L. y A. MORa Enguídanos (2006) Las Normas Internacionales de Información Financiera. Navarra: Thomson Civitas.

EMS COMPAÑÍA DE AUTORES S.L. (2006) Aplicación de las Normas Internacionales de Contabilidad. Adoptadas por la Unión Europea (NICes). Valencia: CISS Grupo Wolters Kluwer.

FINANCIAL ACCOUNTING STANDARS BOARD (FASB) (1991) "Disclosures about Fair Value of Financial Instruments", Statements of Financial Accounting Standar (SFAS), $\mathrm{n}^{\circ} 10$, FASB, Stamford, Connecticut.

- (1993) "Accounting for Certain Investments in Debt and Equity Securities", Statements of Financial Accounting Standar (SFAS), $\mathrm{n}^{\circ} 115$, FASB, Stamford, Connecticut.

INTERNATIONAL ACCOUNTING STANDARDS BOARD (2006) Normas Internacionales de información financiera (NIIF), texto completo de las Normas Internacionales de Información Financiera emitidas a 1 de enero de 2006, traducción al español publicada por CISS-PRAXIS con la autorización de la IASCF.

Pérez Ramírez, J. y J. Calvo González-Vallinas (2006) Instrumentos Financieros. Análisis y valoración con una perspectiva bancaria y de información financiera internacional. Madrid: Pirámide.

REAL DECRETO 1514/2007, de 16 de noviembre, por el que se aprueba el Plan General de Contabilidad. BOE núm. 278, de 20 de noviembre de 2007.

REAL DECRETO 1515/2007, de 16 de noviembre, por el que se aprueba el Plan General de Contabilidad de Pequeñas y Medianas Empresas y los criterios contables específicos para microempresas. BOE núm. 279, de 21 de noviembre de 2007. 